\title{
The Nature of Charge-Transfer Excited States in Transition Metal Complexes Pertinent to Energy Conversion and Chemical Sensing
}

\author{
Néstor E. Katz \\ INQUINOA (UNT-CONICET), Facultad de Bioquímica, Química y Farmacia, Universidad Nacional de Tucumán, San Miguel de \\ Tucumán, Argentina. \\ Email: nkatz@fbqf.unt.edu.ar
}

\begin{abstract}
We present procedures for determining the nature of charge-transfer excited states in transition metal complexes relevant to energy conversion and chemical sensing processes. In particular, we analyze the importance of resorting to both spectroelectrochemical and photophysical techniques to elucidate the "fingerprints" of the intermediates involved in the fate of these reactions. Our contributions to the subject are discussed.
\end{abstract}

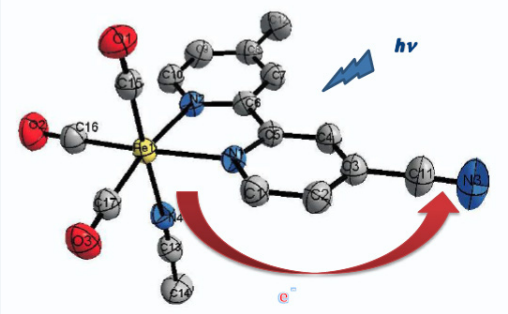

Keywords:

transition metal complexes, energy conversion, chemical sensing

\section{Introduction}

Inspired by the central role of transition metal complexes in natural processes that are fundamental to life on Earth, such as photosynthesis and respiration, inorganic chemists have long recognized that determining the nature of certain chargetransfer excited states can eventually lead to successful conversion of solar energy into electrical or chemical energy as well as to development of new sensing methods for medicinal purposes.

The importance of combining spectroelectrochemical techniques (reaction-oriented electrochemistry with speciesfocused spectroscopy) to analyze redox reactions in general has already been discussed by Kaim et al. ${ }^{1}$ These results can be combined with photophysical techniques in order to identify intermediates involved in electron transfer processes that are relevant to the design of energy conversion schemes or to the discovery of new medical diagnosis and therapies. As a typical example, in a recent work by Keane et $a l^{2}$, the reaction mechanisms involved in the photo-oxidation of guanine in DNA by a Ru complex containing tetraazaphenanthrene ligands were explained by comparing the results obtained by UV-Vis and mid-IR spectroelectrochemical experiments with picosecond transient absorption and time-resolved IR experiments of the mentioned Ru complex bound to DNA.

In our group at INQUINOA (Institute of Chemistry of the Northwest of Argentina), located close to the end of the world, we have been interested since the 1990s in the synthesis and physicochemical characterization of new ruthenium and rhenium complexes that can be applied as photosensitizers in artificial photosynthesis or as sensors of biologically relevant analytes. We have resorted to both spectroelectrochemical and photophysical techniques to elucidate the "fingerprints" of the main intermediates involved in the evolution of charge-transfer processes in which these complexes are involved. This article focuses particularly on our contributions to this field. 


\section{Photosensitizers}

We have recently reported ${ }^{3}$ the synthesis and physicochemical properties of new ruthenium polypyridyl complexes of formulae $\left[\mathrm{Ru}(\mathrm{bpy})_{3-\mathrm{x}}(\mathrm{Mebpy}-\mathrm{CN})_{\mathrm{x}}\right]\left(\mathrm{PF}_{6}\right)_{2}$, (bpy = 2,2'-bipyridine, Mebpy-CN = 4-methyl-2,2'-bipyridine-4'-carbonitrile, $\mathrm{x}=1$ (1), 2 (2), 3 (3)) with the aim of applying them as photosensitizers onto ZnO nanowires. Cation structures in 1-3 are shown in Scheme 1. These complexes have nitrile groups in the periphery of the polypyridyl ligands, which can be used as anchoring entities to $\mathrm{ZnO}$ while preserving the integrity of the nanowires. Following a previous work by McCusker $e t$ $a l .{ }^{4}$, who reported a considerable increase in the lifetimes of excited states of Ru bipyridyl complexes by adding electronwithdrawing substituents such as nitrile groups in the $4,4^{\prime}$ - positions of the bipyridyl rings, we could not only demonstrate that the photosensitizing properties of complexes 1-3 improve with increasing substitution of bpy by Mebpy-CN, but also design new solar cells that convert light into electrical energy by using $\mathrm{TiO}_{2}$ or $\mathrm{ZnO}$ as semiconductors sensitized by these Ru species.

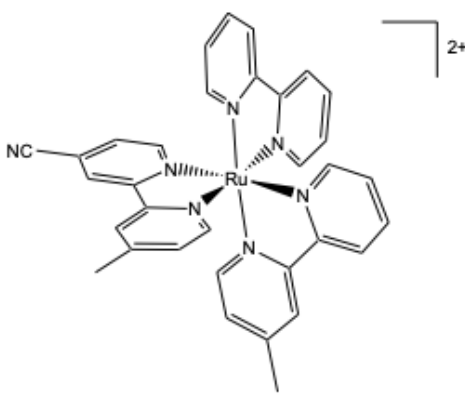

(a)

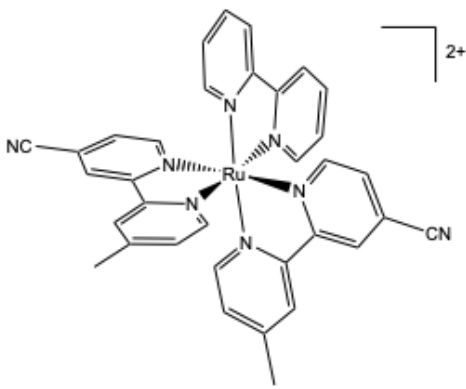

(b)

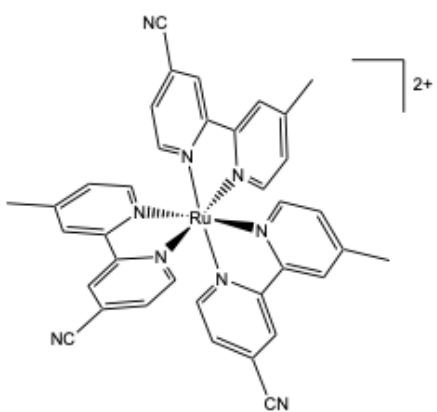

(c)

Scheme 1. Cation structures in complexes 1 (a), 2 (b) and 3 (c).

Spectroelectrochemical studies were carried out on complexes $\mathbf{1}$ - $\mathbf{3}$ in order to know the nature of the oxidized and reduced species. As shown in Figure 1(a), bleaching of the MLCT (metal-to-ligand charge transfer) bands at $\lambda_{\max }=$ 450-470 $\mathrm{nm}$ is observed when oxidizing the metallic center. New IL (intraligand) bands appear at $\lambda_{\max }=330 \mathrm{~nm}$ with intensities increasing along the series. After reducing Mebpy-CN, as shown in Figure 1(b), new bands appear at $\lambda_{\max }=350$ $\mathrm{nm}$, which are typical of bpy radicals. ${ }^{5}$ These data can be compared to the photophysical properties of transient species that are described in the next paragraph. All the studied complexes exhibited an almost complete recovery of the initial spectra when re-oxidized or re-reduced. 


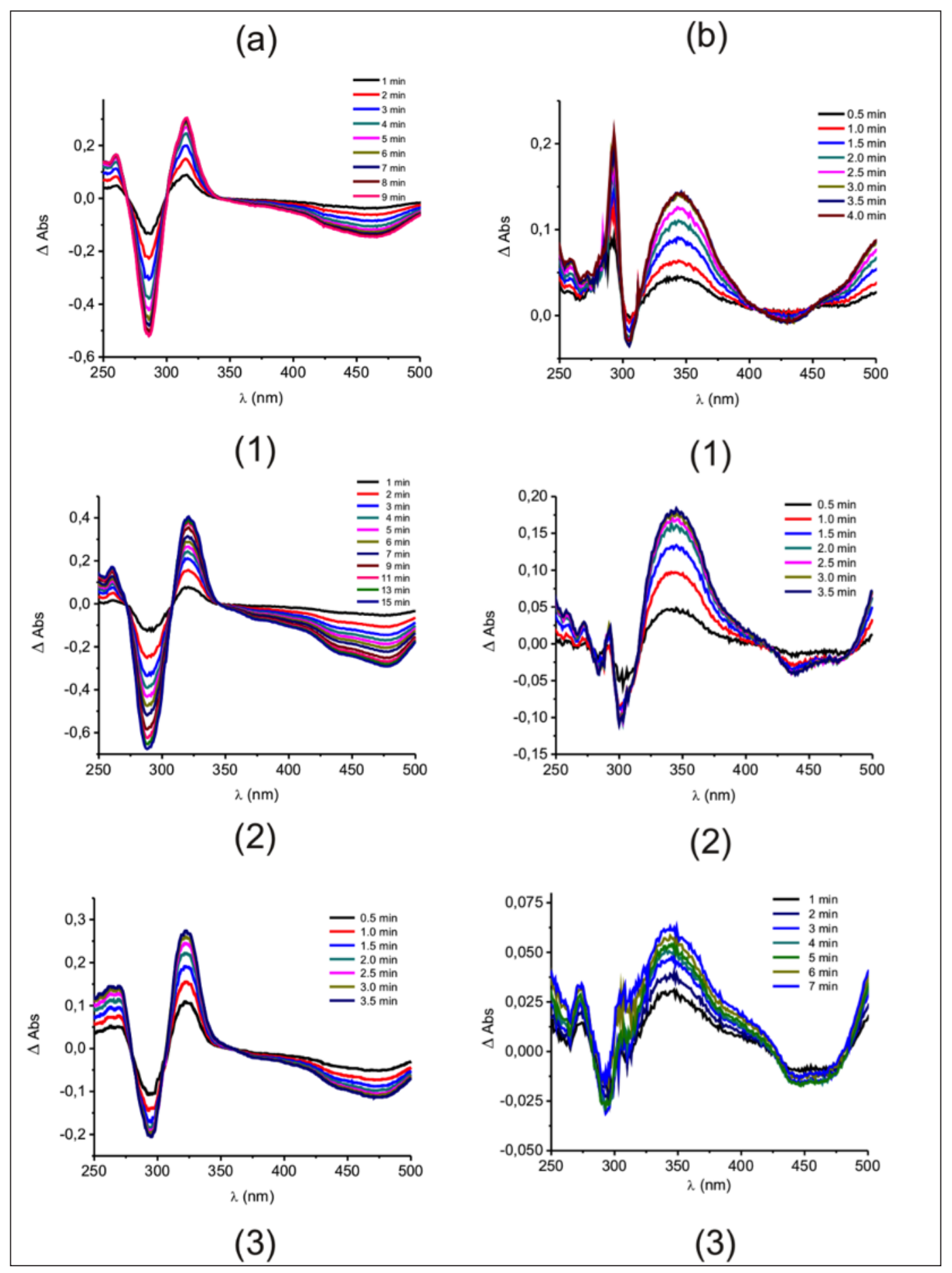

Figure 1. (a) Oxidative difference spectra acquired at an applied potential $150 \mathrm{mV}$ higher than the oxidation potential of the metallic center of 1, 2 and 3, from top to bottom, respectively. (b) Reductive difference spectra acquired at an applied potential $75 \mathrm{mV}$ lower than the first reduction potential of $\mathbf{1 , 2}$ and $\mathbf{3}$, from top to bottom, respectively.

The photophysical properties of complexes 1-3 in $\mathrm{CH}_{3} \mathrm{CN}$ at room temperature are summarized in Table 1. They all exhibit higher emission quantum yields $\left(\varphi_{\mathrm{em}}\right)$ and higher lifetimes $(\tau)$ for the lowest ${ }^{3}$ MLCT excited states than those of prototype complex $\left[\mathrm{Ru}(\mathrm{bpy})_{3}\right]\left(\mathrm{PF}_{6}\right)_{2}$, measured under the same conditions $\left(\varphi_{\mathrm{em}}=0.095\right.$ and $\tau=0.66 \mu \mathrm{s}$, respectively). Both values increase with increasing substitution of bpy by Mebpy- $\mathrm{CN}$, indicating a higher delocalization induced by the nitrile groups, as described before by McCusker et al. ${ }^{4}$ for the $4,4^{\prime}$-disubstituted bipyridyl species. The correlation between luminescence quantum yields and emission lifetimes has already been reported in a different series of ruthenium(II) polypyridyl complexes. $^{6}$ 
Table 1. Photophysical properties of complexes 1-3 in $\mathrm{CH}_{3} \mathrm{CN}$, at r.t. (room temperature).

\begin{tabular}{|l|l|l|l|l|l|l|}
\hline Complex & $\lambda_{\mathrm{em}}(\mathrm{nm})$ & $\varphi_{\mathrm{em}}$ & $\tau / \mu \mathrm{s}^{a}$ & $k_{\mathrm{obs}} \times 10^{-5} / \mathrm{s}^{-1}$ & $k_{\mathrm{r}} \times 10^{-5} / \mathrm{s}^{-1} b$ & $k_{\mathrm{nr}} \times 10^{-5} / \mathrm{s}^{-1} c$ \\
\hline $\mathbf{1}$ & 623 & 0.120 & $0.76(0.73)$ & 13.2 & 1.58 & 11.6 \\
\hline $\mathbf{2}$ & 660 & 0.125 & $0.97(1.09)$ & 10.3 & 1.28 & 9.0 \\
\hline $\mathbf{3}$ & 658 & 0.133 & $1.16(1.22)$ & 8.6 & 1.14 & 7.5 \\
\hline
\end{tabular}

${ }^{a}$ Data obtained by LFP (in parentheses, by TCSPC). ${ }^{b} k_{\mathrm{r}}=\varphi^{\mathrm{em}} \cdot k_{\mathrm{obs}} \cdot{ }^{c} k_{\mathrm{nr}}=k_{\mathrm{obs}}-k_{\mathrm{r}}$.

Figure 2 shows the time-resolved differential absorption spectra of complexes 1-3 obtained by LFP (laser flash photolysis), a powerful technique used to detect intermediates in light-induced processes. In all cases, bleaching of the MLCT bands at $\lambda_{\max }=450-470 \mathrm{~nm}$ was observed, which can be explained by the presence of $\mathrm{Ru}^{\mathrm{III}}$ in the excited state. Additionally, new bands appear at $\lambda_{\max }=370 \mathrm{~nm}$, assigned to IL transitions of the Mebpy-CN radical, and at $\lambda_{\max }=330 \mathrm{~nm}$, associated to IL bands of the neutral ligands. As shown in Table 1, the lifetimes obtained by LFP agree, within experimental error, with those obtained by TCSPC (time-correlated single photon counting), another important photophysical technique used for determining a wide range of lifetimes of excited states in luminescent compounds.

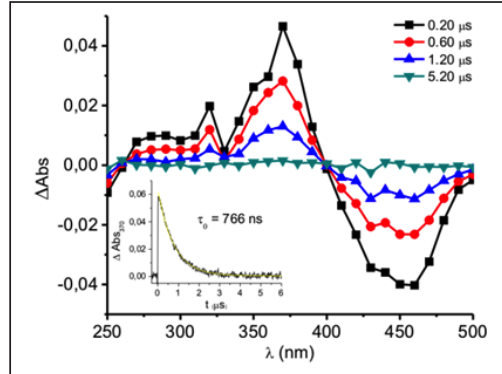

(1)

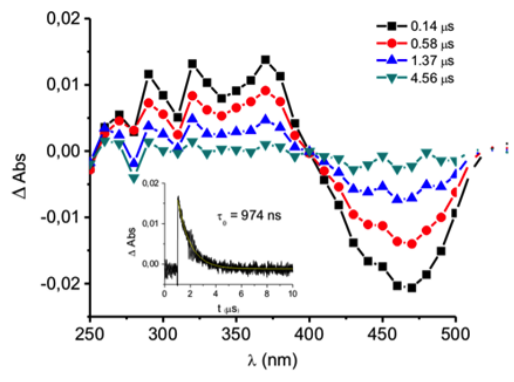

(2)

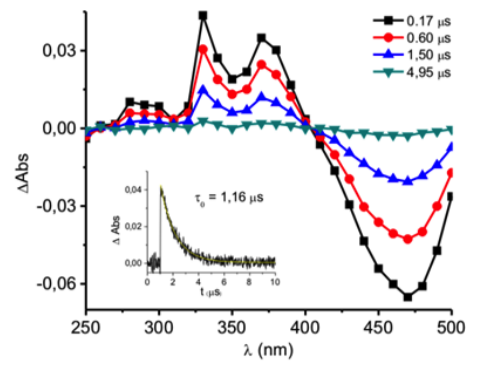

(3)

Figure 2. Time-resolved differential absorption spectra of $\mathbf{1}$ (top), $\mathbf{2}$ (middle) and $\mathbf{3}$ (bottom) in $\mathrm{CH}_{3} \mathrm{CN}$ at different times $(0.14-5.20 \mu \mathrm{s}), \lambda_{\text {exc }}=370 \mathrm{~nm}$, obtained by LFP. Insets: absorbance decays at $370 \mathrm{~nm}$ and mono-exponential fittings. 
The spectroelectrochemical measurements described before are consistent with these findings: a new band appears at $\lambda_{\max }=350 \mathrm{~nm}$ when the complexes are reduced (displaced by charge effects in relation to the band at $\lambda_{\max }=370 \mathrm{~nm}$ observed in LFP) and a new band appears at $\lambda_{\max }=330 \mathrm{~nm}$ when the complexes are oxidized, both of them associated to IL transitions. The MLCT bands disappear when oxidizing the metal. Based on both techniques, the lowest-lying MLCT excited states in all complexes (1-3) can thus be formulated as charge-separated species $\left[\mathrm{Ru}^{\mathrm{III}}-\left(\mathrm{Mebpy}-\mathrm{CN}^{\cdot} \cdot^{-}\right)\right]$.

The experimental data described above can be explained by DFT (density functional theory) calculations, from which a detailed description of the molecular orbitals (MO) of coordination compounds, such as those described in this work, can be extracted. Indeed, as shown in Figure 3, the HOMOs (highest occupied molecular orbitals) in complexes 1-3 are all centered in only one $\mathrm{d}$ orbital of the Ru center. The LUMOs (lowest unoccupied molecular orbitals) in the same species are delocalized over the Mebpy-CN ligands; therefore, the lowest-lying energy absorption bands can be assigned to MLCT transitions from a non-bonding Ru orbital to an antibonding orbital of Mebpy-CN for all complexes. These pictures of molecular orbitals indicate the highest probabilities of electron densities and can be made by using programs such as GaussSum. ${ }^{7}$ Calculated orbital energies are consistent with the redox potentials measured by electrochemical methods and disclose an increasing stabilization of the bipyridyl ligands when going from $\mathbf{1}$ to $\mathbf{3}$, a result of importance for designing better sensitizers in solar cells that can absorb further in the IR region.

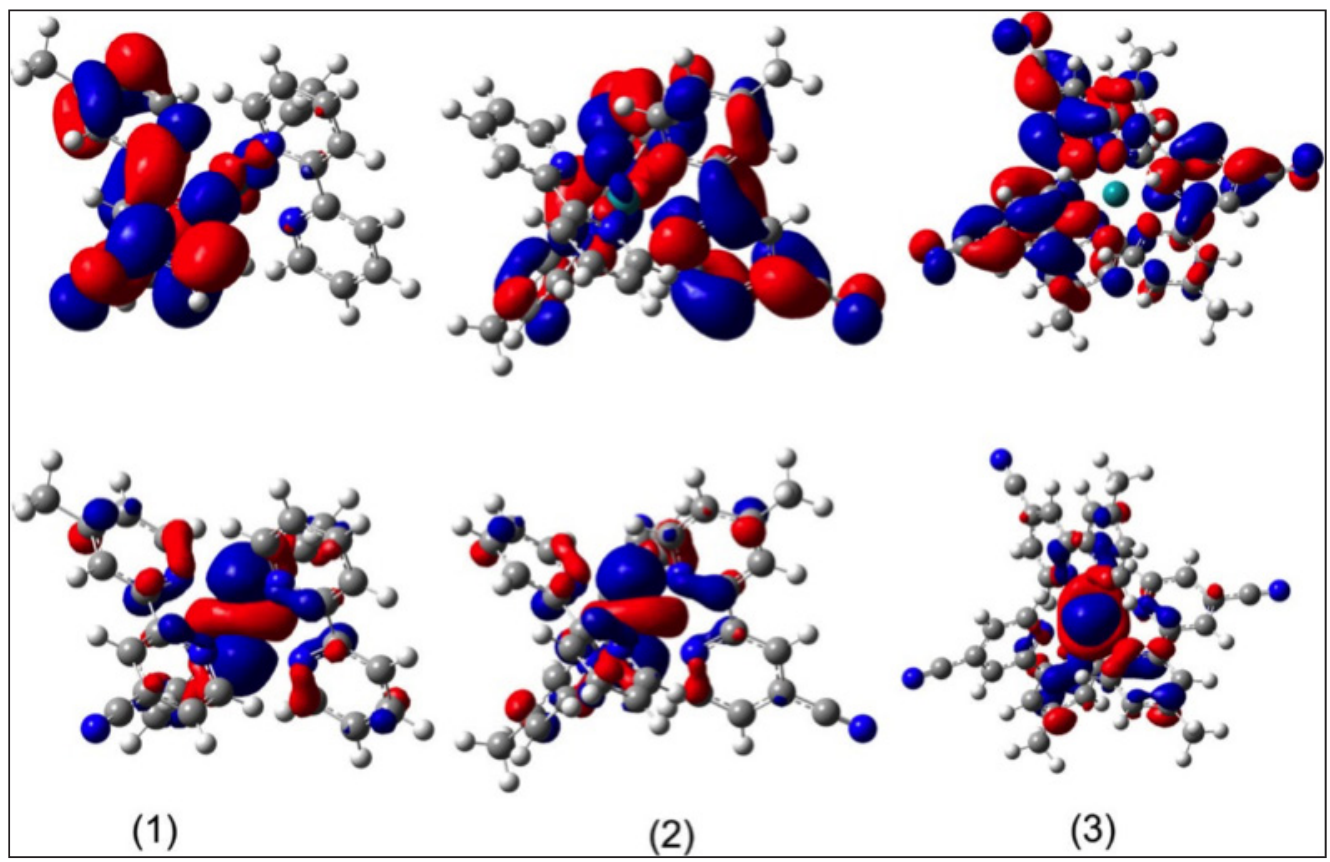

Figure 3. Pictures of LUMOs (top) and HOMOs (bottom) in complexes 1-3.

In order to test the applications of these complexes in dye-sensitized solar cells (DSCs), we first anchored them on the surface of porous $\mathrm{TiO}_{2}$ films. ${ }^{8}$ The nitrile groups are linked to this nanocrystalline semiconductor, as evidenced by Raman spectra of the adsorbed species. In effect, the nitrile stretching frequency appearing at $2240 \mathrm{~cm}^{-1}$ in the pure complexes is displaced to $2333 \mathrm{~cm}^{-1}$ in the same complexes adsorbed onto $\mathrm{TiO}_{2}$. This large positive shift indicates coordination of the free $\mathrm{N}$ of the nitrile group to a $\mathrm{Ti}^{4+}$ center. Solar cells can be built with these sensitized electrodes, a Pt-counter electrode and iodine/iodide as a redox mediator electrolyte dissolved in a polymeric matrix. When irradiated by a solar simulator, the cells assembled with the $\mathrm{Ru}$ complexes (2) and (3) as $\mathrm{TiO}_{2}$ sensitizers exhibited almost identical current-potential curves, with short-circuit photocurrents of $1.25 \mathrm{~mA} \mathrm{~cm}^{-2}$, fill factors of 0.5 , and overall efficiencies around $0.4 \%{ }^{8}$ The $\mathrm{Ru}$ complex (1) and a similar Re complex with formula $\mathrm{Re}(\mathrm{Mepbpy}-\mathrm{CN})(\mathrm{CO})_{3} \mathrm{Cl}(\mathbf{R e L})$ did not perform as well as sensitizers. These results were consistent with those obtained from quantum efficiency curves and impedance spectra.

The quantum efficiency $(Q E)$ spectra of these solar cells, acquired at $(25 \pm 1){ }^{\circ} \mathrm{C}$, are shown in Figure $4(\mathrm{a}) . Q E$ values were calculated as the ratio of the number of carriers collected by the solar cell to the number of photons of a given energy incident on it. Figure 4(b) shows the current-potential curves obtained under irradiation with the solar simulator (linear sweep voltammetry, $\left.5 \mathrm{mV} \mathrm{s}^{-1}\right)$ at $(30 \pm 1){ }^{\circ} \mathrm{C}$. From these $I$ - $V$ curves, the efficiency of conversion of light into electrical energy could be determined for each cell. ${ }^{8}$ 


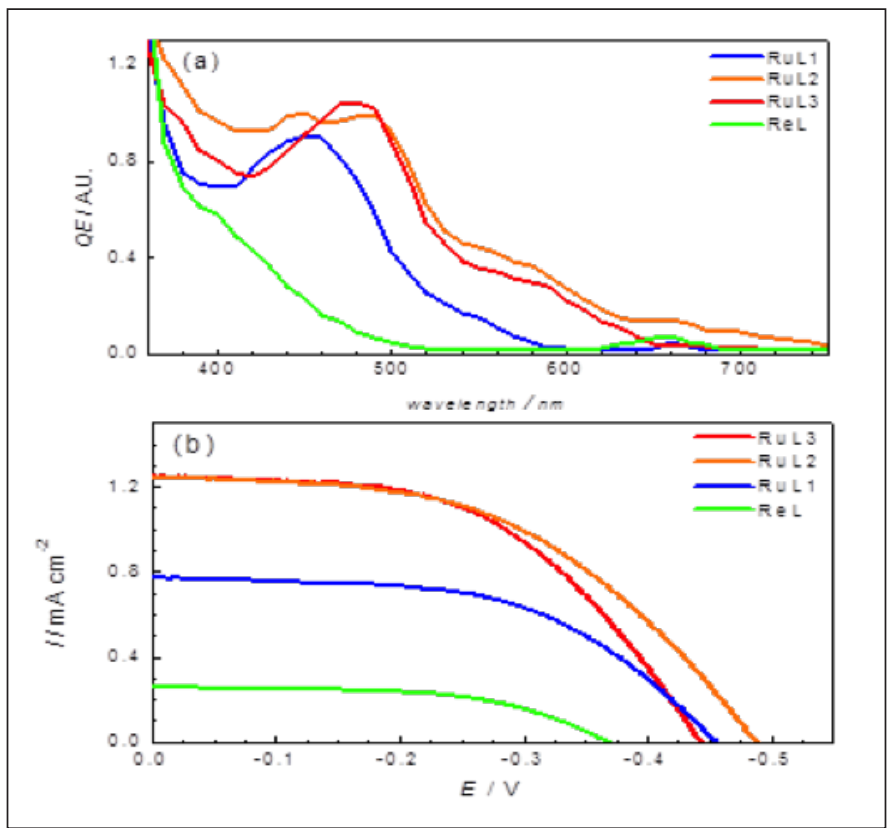

Figure 4. Solar cells $\left(1 \mathrm{~cm}^{2}\right)$ assembled with $\mathrm{TiO}_{2}$ sensitized with RuL1(1), RuL2 (2), RuL3 (3) and ReL: (a) quantum efficiencies spectra and (b) current-potential curves under polychromatic irradiation.

From Figure 4(a), it can be deduced that, except for the solar cell assembled with ReL-sensitized $\mathrm{TiO}_{2}$, the higher efficiencies were observed for incident radiation with wavelengths between 460 and $520 \mathrm{~nm}$, in excellent agreement with the UV-Vis spectra of sensitized $\mathrm{TiO}_{2}$ films. By comparing $Q E$ and $I-V$ curves in Figure 4, a similar performance under irradiation was disclosed for the cells assembled with complexes (2) and (3) as $\mathrm{TiO}_{2}$ sensitizers, exhibiting overall efficiency values $\eta=0.44 \%$. The lower performance of (1) can be associated with less amount of adsorbed complex, while the poor performance of the ReL solar cell can be related to its extremely low absorption in the visible region. We thus conclude that ruthenium bipyridyls substituted with nitrile groups can be considered as promising candidates for sensitizing semiconductors used in the design of novel DSCs.

Based on the previous conclusion, we have recently synthesized new ruthenium polypyridyl complexes whose physicochemical properties can be modulated by structural modifications adequate for increasing efficiency of the energy conversion process in DSCs. ${ }^{9}$ These species, with formulae $\left[\mathrm{Ru}\left(4,4^{\prime}-\mathrm{X}_{2}-\mathrm{bpy}\right)_{2}(\mathrm{Mebpy}-\mathrm{CN})\right]\left(\mathrm{PF}_{6}\right)_{2}$, where $\mathrm{X}=\mathrm{CH}_{3}(4), \mathrm{X}$ $=\mathrm{OCH}_{3}(\mathbf{5})$ and $\mathrm{X}=\mathrm{N}\left(\mathrm{CH}_{3}\right)_{2}(\mathbf{6})$, whose structures are shown in Scheme 2, have been characterized by electrochemical, spectroscopic and photophysical techniques.

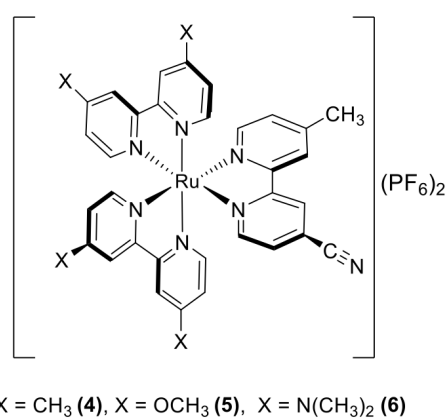

Scheme 2. Structures of the complexes $\left[\mathrm{Ru}\left(4,4^{\prime}-\mathrm{X}_{2}-\text { bpy }\right)_{2}(\mathrm{Mebpy}-\mathrm{CN})\right]\left(\mathrm{PF}_{6}\right)_{2}$

As the electron donor strength of $\mathrm{X}$ in the $4,4^{\prime}-\mathrm{X}_{2}$-bpy ligand increases when going from (4) to (6), a cathodic shift of the redox potentials of the $\mathrm{Ru}^{\mathrm{II}} / \mathrm{Ru}^{\mathrm{II}}$ couples $\left(E_{1 / 2}=1.23,1.06\right.$ and $0.72 \mathrm{~V}$, in $\mathrm{CH}_{3} \mathrm{CN}$, vs. SCE) and displacements towards lower energies of the absorption and emission maxima in $\mathrm{CH}_{3} \mathrm{CN}\left(\lambda_{\max } / \lambda_{\mathrm{em}}=475 / 666,485 / 707\right.$ and $\left.530 / 800 \mathrm{~nm}\right)$ were 
observed, consistent with quantum mechanical calculations. The emission quantum yields and the lifetimes of the excited states in $\mathrm{CH}_{3} \mathrm{CN}$ saturated with $\operatorname{Ar}(\tau=672,322$ and $21 \mathrm{~ns})$ decreased in the same order, according to the energy gap law.

The three complexes were anchored by the nitrile group to the surface of $\mathrm{ZnO}$ nanowires, which were grown in FTO (fluorine-doped tin oxide) glasses using a hydrothermal technique, and they all showed promising photosensitizing properties for the design of new solar cells.

Another example of a correlation between spectroelectrochemical and photopysical measurements helpful for disclosing the nature of light-induced excited states has been described in our recent work ${ }^{10}$ concerning the properties of a rhenium(I) complex of formula $\left[\mathrm{Re}(\mathrm{Mebpy}-\mathrm{CN})(\mathrm{CO})_{3}\left(\mathrm{CH}_{3} \mathrm{CN}\right)\right]^{+},(7)$, whose structure is displayed in Scheme 3 , as an ORTEP diagram deduced from X-ray diffraction data.

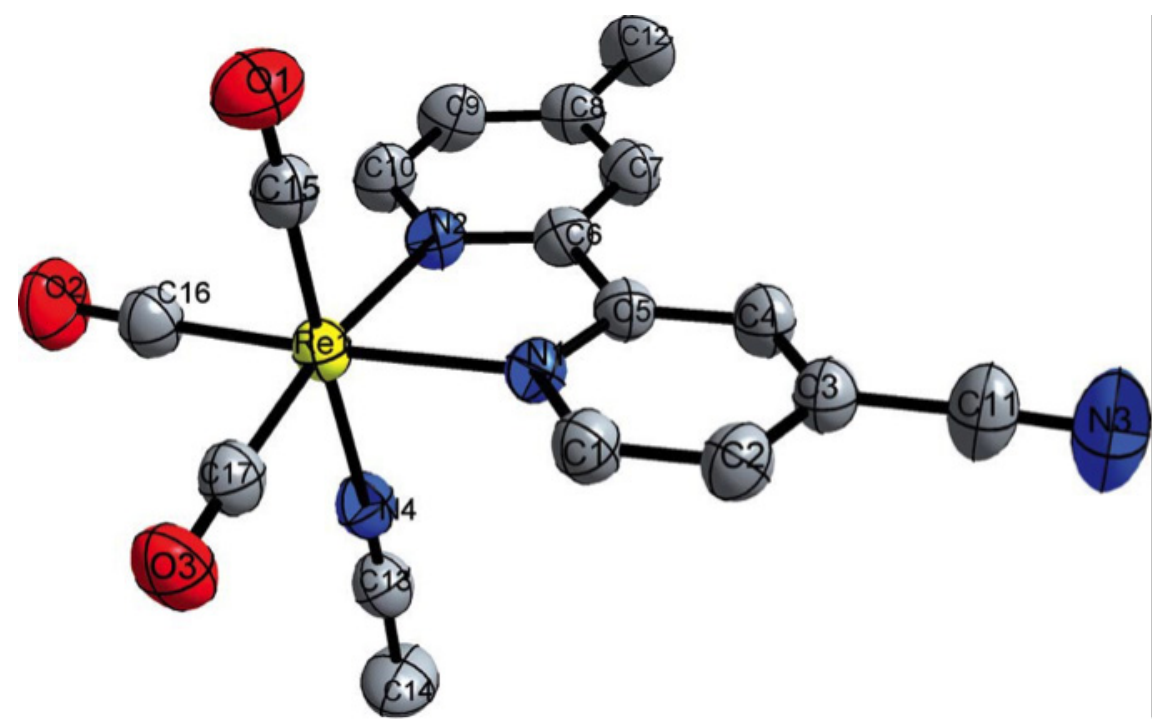

Scheme 3. Structure of $\left[\mathrm{Re}(\mathrm{Mebpy}-\mathrm{CN})(\mathrm{CO})_{3}\left(\mathrm{CH}_{3} \mathrm{CN}\right)\right]^{+}$, (7). The different colors indicate the following atoms: Re (yellow), $\mathrm{C}$ (black), $\mathrm{N}$ (blue) and $\mathrm{O}$ (red). All $\mathrm{H}$ atoms have been omitted for clarity reasons.

As shown in Figure 5, UV-Vis spectroelectrochemistry for this cation at an applied potential of $V=-0.9 \mathrm{~V}$, resulted in the bleaching of the MLCT band (from a d orbital of Re to a $\pi^{*}$ orbital of bpy) at $\lambda_{\max }=350 \mathrm{~nm}$ and the appearance of new bands at $\lambda_{\max }=370$ and $450 \mathrm{~nm}$, which are consistent with the generation of the radical anion Mebpy-CN $\cdot^{-}$. Reoxidation at $V=-0.7 \mathrm{~V}$, produced an almost total recovery of the original complex.

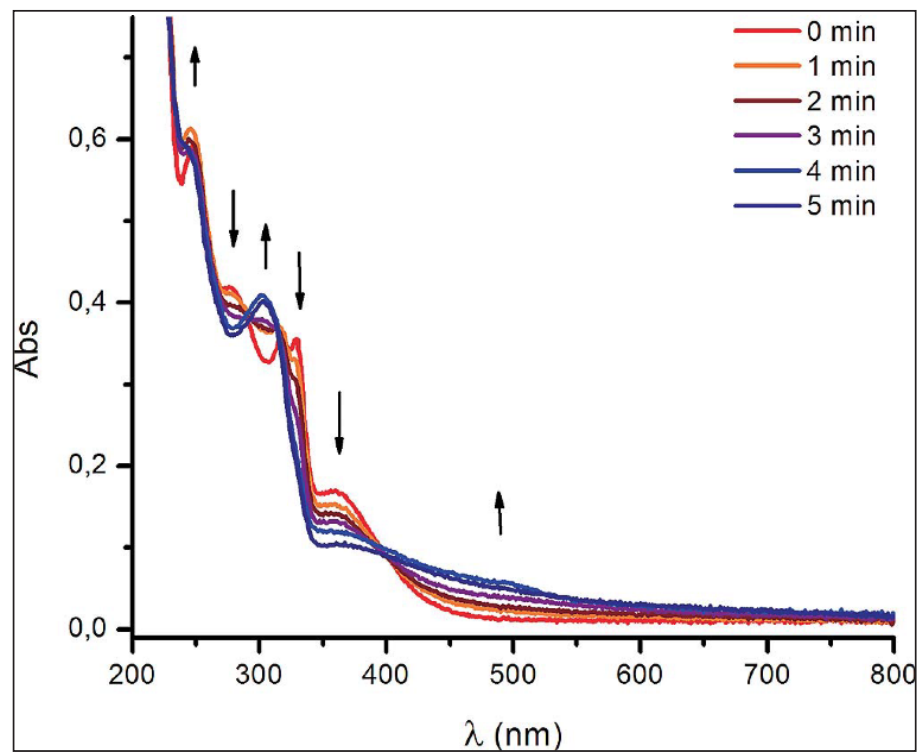

Figure 5. UV/Vis spectroelectrochemistry of (7) in $\mathrm{CH}_{3} \mathrm{CN}, 0.1 \mathrm{M} \mathrm{TBAH}$, at $V=-0.9 \mathrm{~V}$. 
Figure 6 shows the transient spectra obtained at different times for the excited state of (7), as detected by LFP. The band maxima observed at $\lambda_{\max }=370$ and $460 \mathrm{~nm}$ correspond to IL transitions of Mebpy-CN.- Similar values were observed in the time-resolved UV-Vis spectrum of excited $\left[\mathrm{Re}(\mathrm{bpy})(\mathrm{CO})_{3} \mathrm{Cl}\right] .{ }^{11}$ This assignment is consistent with the reduction experiments described in the paragraph above, as well as with the transient spectra observed for ruthenium complexes with Mebpy-CN. Excited states lifetimes were determined both by LFP $(\tau=293$ ns, as indicated in Figure 6 ) and TCSPC ( $\tau=283 \mathrm{~ns})$; they were both mono-exponential and equal within experimental error, thus supporting the assignment of the emitting state as the charge-separated species $\left[\mathrm{Re}^{\mathrm{II}}-\left(\mathrm{Mebpy}-\mathrm{CN}{ }^{-}\right)\right]$.

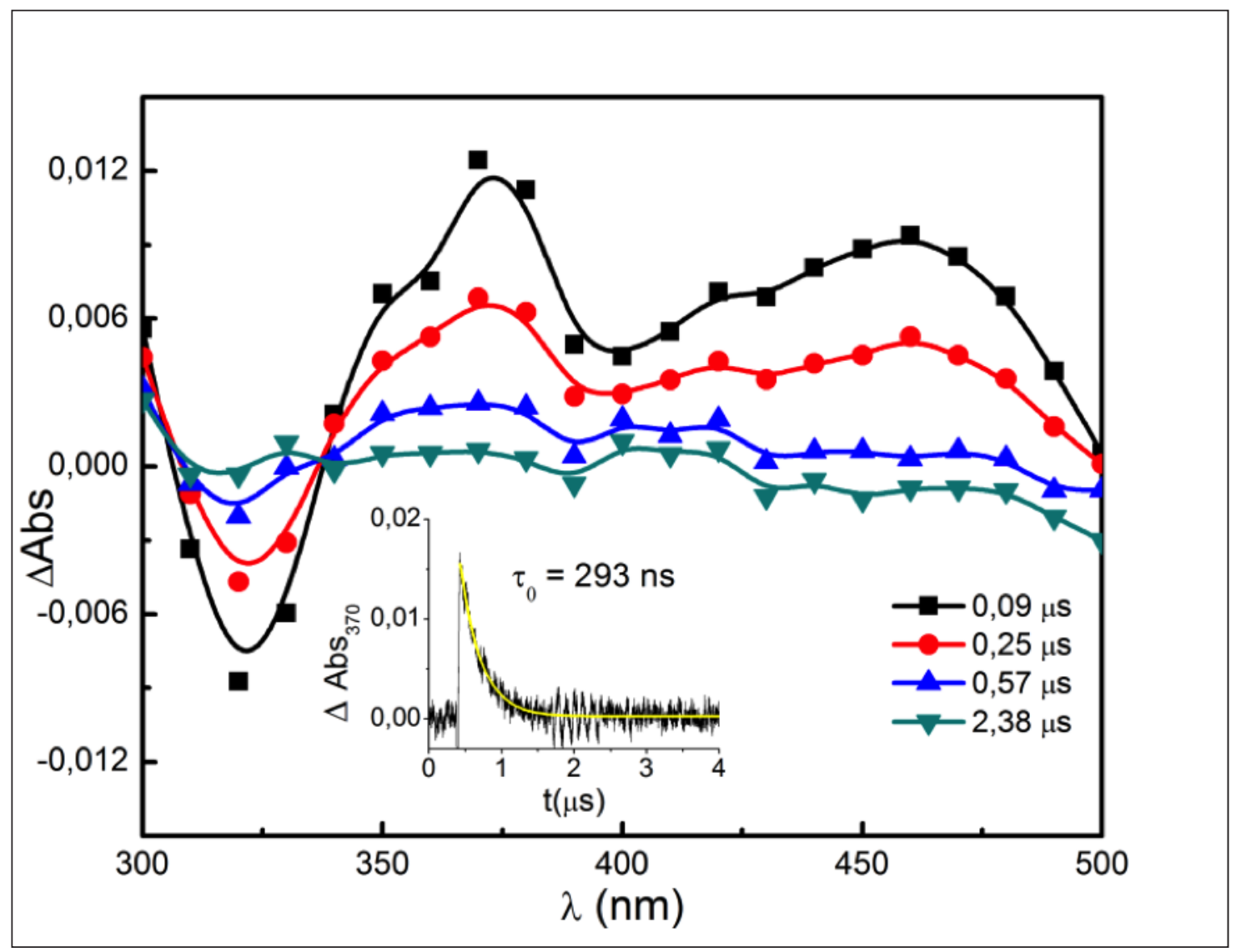

Figure 6. Transient spectra for the excited state of complex (7) in $\mathrm{CH}_{3} \mathrm{CN}$ at r.t. obtained by LFP. Inset: transient absorption decay monitored at $\lambda=370 \mathrm{~nm}$.

We conclude that spectroelectrochemical data for this triscarbonylrhenium(I) complex are fully compatible with transient absorption measurements, as was the case with the previously described series of polypyridylruthenium(II) complexes. However, using Re complexes as sensitizers in solar cells is limited by the small amount of visible light that they can absorb.

Using quantum mechanical DFT calculations, the compositions of some frontier MOs for complex (7) could be determined, as shown in Table 2. 
Table 2. Energies and percent contributions of the 3 highest HOMOs and the 3 lowest LUMOs for the ground state of complex (7).

\begin{tabular}{|l|c|c|c|c|c|}
\hline \multicolumn{1}{|c|}{ MO } & $E(\mathrm{eV})$ & $\mathrm{Re}(\%)$ & Me-bpyCN (\%) & CO's(\%) & AN(\%) \\
\hline LUMO+2 & -1.73 & 2 & 91 & 6 & 0 \\
\hline LUMO+1 & -2.40 & 0 & 99 & 1 & 0 \\
\hline LUMO & -3.29 & 2 & 93 & 4 & 0 \\
\hline HOMO & -7.29 & 60 & 10 & 25 & 5 \\
\hline HOMO - 1 & -7.40 & 61 & 10 & 23 & 5 \\
\hline HOMO -2 & -7.62 & 69 & 2 & 29 & 0 \\
\hline
\end{tabular}

The LUMO is centered at the Mebpy-CN ligand, but the mixing between $\mathrm{d}_{\pi}(\mathrm{Re})$ and CO orbitals in the HOMO of (7) indicates that the lowest energy lying absorption band of (7) can be assigned to a MLLCT (metal-ligand to ligand charge transfer) transition. The EDDM (electron-density difference map) for this band can thus be envisaged as a transfer of electronic density from the $\mathrm{Re}(\mathrm{CO})_{3}$ fragment to Mebpy-CN. LUMO and HOMO diagrams for complex (7) are displayed in Figure 7.
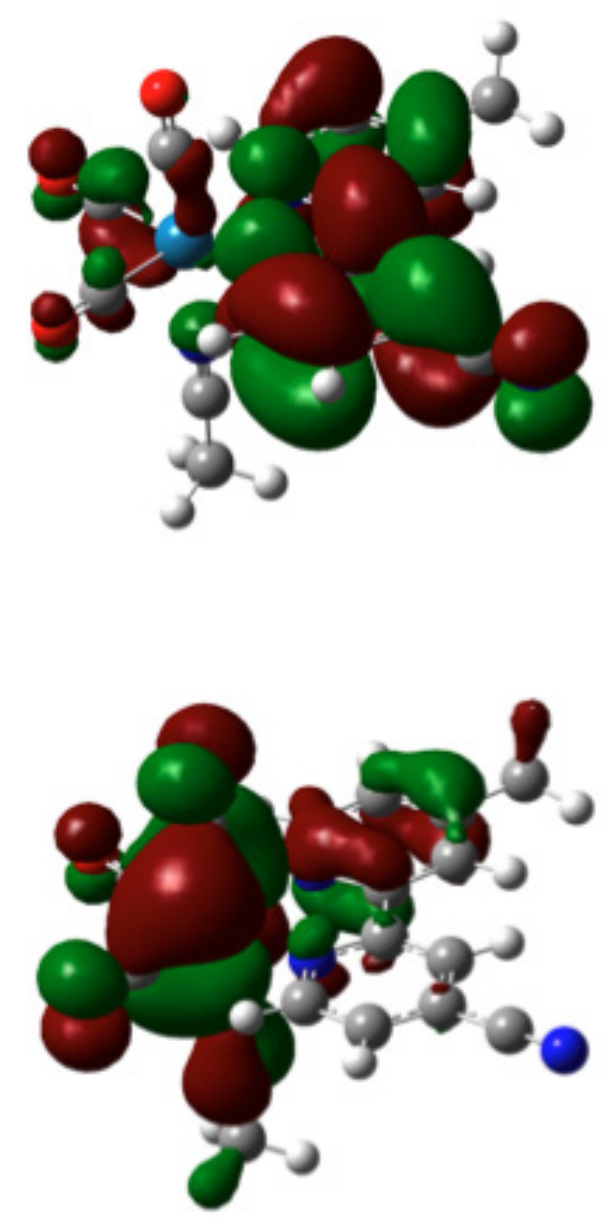

Figure 7. Pictures of LUMO (top) and HOMO (bottom) of complex (7). 
The calculated UV-Vis spectrum of complex (7) matches with its experimental spectrum reasonably well, confirming the assignment of charge-transfer transitions.

\section{Sensors}

The parallel use of spectroscopic measurements with photophysical studies can also help to elucidate the nature of chargetransfer excited states relevant in chemical sensing.

As a prototypical example, we have recently reported ${ }^{12}$ the synthesis and physicochemical properties of a new binuclear complex of formula $\left[\left(\mathrm{CH}_{3} \mathrm{CN}\right)(\mathrm{CO})_{3} \operatorname{Re}\left(4,4^{\prime \prime}\right.\right.$-azobpy) $\left.\operatorname{Re}(\mathrm{CO})_{3}\left(\mathrm{CH}_{3} \mathrm{CN}\right)\right]\left(\mathrm{PF}_{6}\right)_{2}$, (8), with 4,4"'-azobpy = 4,4"'-azobis(2,2'-bipyridine). The symmetrical structure of the cationic part in (8), as deduced from NMR data, is shown in Scheme 4.

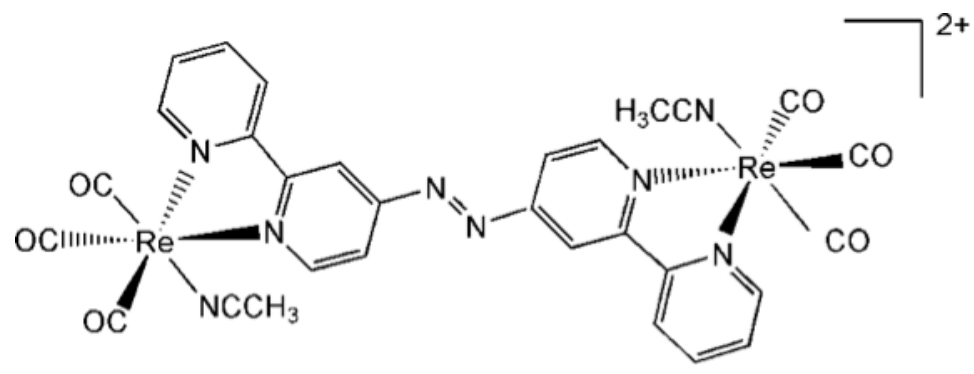

Scheme 4. Structure of the cation in complex (8).

The UV-Vis spectrum of $(\mathbf{8})$ in $\mathrm{CH}_{3} \mathrm{CN}$ is shown in Figure 8 . The bands at $\lambda<300 \mathrm{~nm}$ were assigned to IL transitions by comparison with those observed for free 4,4"'-azobpy. The broad band between $300 \mathrm{~nm}$ and $500 \mathrm{~nm}$ could be deconvoluted into two components (at $\lambda_{\max }=346$ and $400 \mathrm{~nm}$ ) which were assigned to MLCT $\mathrm{d}_{\pi}(\operatorname{Re}) \rightarrow \pi^{*}\left(4,4^{\prime \prime}\right.$-azobpy) transitions. The band at the lower energy level was attributed to electron promotion from the HOMO mainly localized in the metal to the LUMO mainly localized in the azo bridge. On the other hand, the higher energy band was attributed to a transition from the HOMO to the LUMO+1 mainly localized in the bipyridyl rings. These assignments were confirmed by DFT calculations.

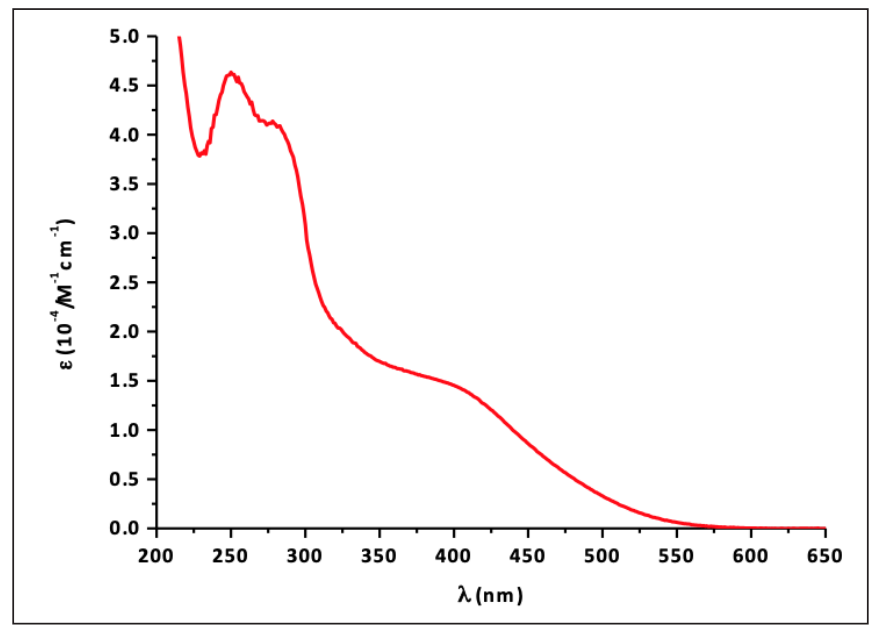

Figure 8. UV-Vis spectrum of complex $(8)$ in $\mathrm{CH}_{3} \mathrm{CN}$.

When applying an external potential $V=-316 \mathrm{mV}$ to the spectroelectrochemical cell filled with a solution of $(\mathbf{8})(C$ $\left.=10^{-4} \mathrm{M}\right)$ in $\mathrm{CH}_{3} \mathrm{CN}$, a decrease in the intensity of IL transition bands can be observed, while new bands appear at $\lambda_{\max }$ $=460,550$ and $800 \mathrm{~nm}$, attributed to IL transitions of the azobpy- radical, as expected after 1-electron reduction of (8). These bands are similar to those reported for Re complexes containing reduced azo ligands. ${ }^{13}$ The shift to higher energies 
of the MLCT band at $\lambda_{\max }=400 \mathrm{~nm}$ can be explained by the increase of electron density in the bridging ligand upon reduction and the subsequent destabilization of the HOMO Re $\left(\mathrm{d}_{\pi}\right)$ orbitals. When the applied potential is restored to 0 $\mathrm{V}$, the original spectrum can be fully recovered, in agreement with voltammetric studies. When an external potential of $V$ $=-800 \mathrm{mV}$ is applied, the intensities of the bands attributed to the radical increase when compared to the first 1-electron reduction, and the MLCT band shifts to even higher energies. As shown in Figure 9, the UV-Vis spectra of the 2-electron reduction processes can be split into two sets: the first one corresponds to the first 1-electron reduction with an isosbestic point at $\lambda=395 \mathrm{~nm}$, and the second one corresponds to the subsequent 2-electron reduction with two isosbestic points at $\lambda=449 \mathrm{~nm}$ and $595 \mathrm{~nm}$.

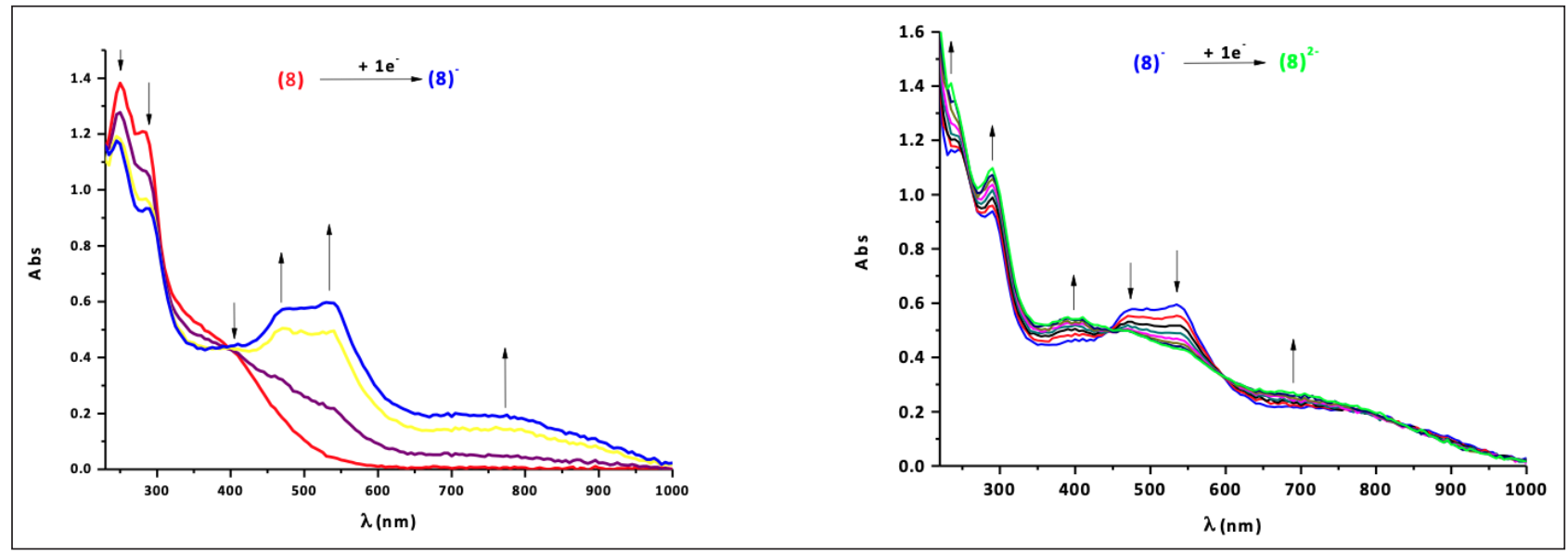

Figure 9. UV-Vis absorption changes in (8) after applying an external potential of $V=-800 \mathrm{mV}$ split into two subsequent 1-electron processes.

Results from UV-Vis spectroelectrochemistry can be nicely compared with changes observed in FT-IR spectroelectrochemical experiments. In effect, by using an IR spectroelectrochemical cell with an applied external potential $V=-316 \mathrm{mV}$, the frequencies corresponding to $\mathrm{v}(\mathrm{C} \equiv \mathrm{O})$ of the carbonyl groups in $(8)$ shift to lower energies, with the band assigned to $\mathrm{CO}_{\text {eq }}$ groups (those at lower energy) being more affected. Isosbestic points are detected at 2036 and $1932 \mathrm{~cm}^{-1}$, This effect can be explained by considering that the electron withdrawing character of the 4,4" -azobpy ligand is diminished when its electron density increases upon reduction, leading to an increase of the $\pi$-backbonding effect from the metallic center to the $\mathrm{CO}$ ligands, and a consequent decrease of $\mathrm{CO}$ bond orders. Vibrational frequencies in diatomic species are proportional to the square root of the strength of the chemical bond between two atoms (as measured by its force constant). ${ }^{14}$ The frequencies of $\mathrm{CO}_{\text {eq }}$ groups are more affected, since they have adequate symmetry to interact with the metal orbitals, as opposed to $\mathrm{CO}_{\mathrm{ax}}$ groups that are orthogonal to the $4,4{ }^{\prime \prime}$-azobpy ligand. ${ }^{15}$ When the applied potential is restored to $0 \mathrm{~V}$, the original spectrum is fully recovered.

As shown in Figure 10, when an external potential $V=-770 \mathrm{mV}$ is applied, more pronounced shifts to lower energies of $\mathrm{CO}$ bands frequencies are observed as a consequence of the 2-electron reduction process of 4,4" -azobpy. Isosbestic points are also detected, and the spectrum of the 1-electron reduction product can be observed at the beginning of the reduction.

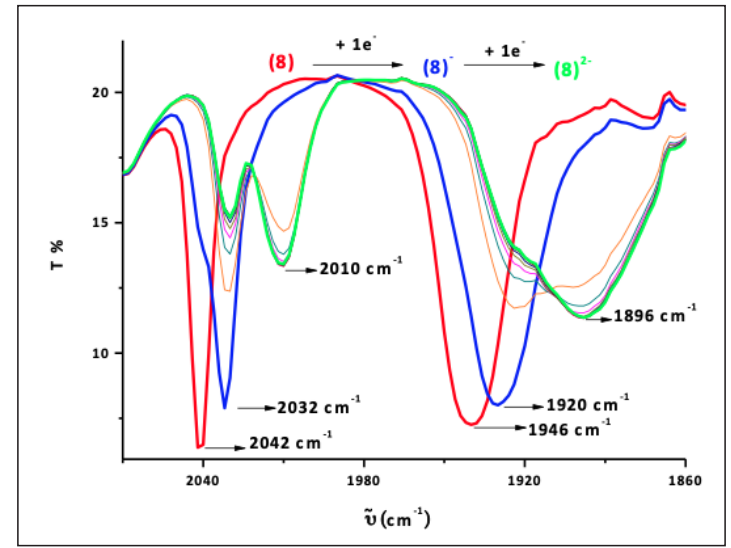

Figure 10. IR subsequent changes upon reduction of $(8)$ in $\mathrm{CH}_{3} \mathrm{CN}$ at $V=-770 \mathrm{mV}$. 
The UV-Vis spectral changes of (8) upon addition of excess of the reductant $L$-Cysteine ( $L$-Cys) were measured in a $\mathrm{H}_{2} \mathrm{O} / \mathrm{CH}_{3} \mathrm{CN}$ mixture $(1: 1)$ at $\mathrm{pH}=6$. After reduction, the LUMO is populated and the band at $\lambda_{\max }=400 \mathrm{~nm}$ (assigned to the lowest energy MLCT) disappears, while a new CT band is observed at $\lambda_{\max }=342 \mathrm{~nm}$, as shown in Figure 11. On the other hand, a new band appears at $\lambda_{\max }=312 \mathrm{~nm}$ that can be assigned to a MLCT from the HOMO to the LUMO +1 . Reaching the ratio $[L-C y s] /[$ complex $] 2: 1$, no changes on the UV-Vis spectra have been detected, thus pointing to a double reduction of the azo group. This chemical reduction is also reversible when the solution is exposed to atmospheric oxygen. The detection limit was determined to be in the submicromolar region, so that this rhenium complex can be used for sensing L-Cys; abnormal levels of thiols in human blood are indicative of diverse neurological diseases. ${ }^{16}$

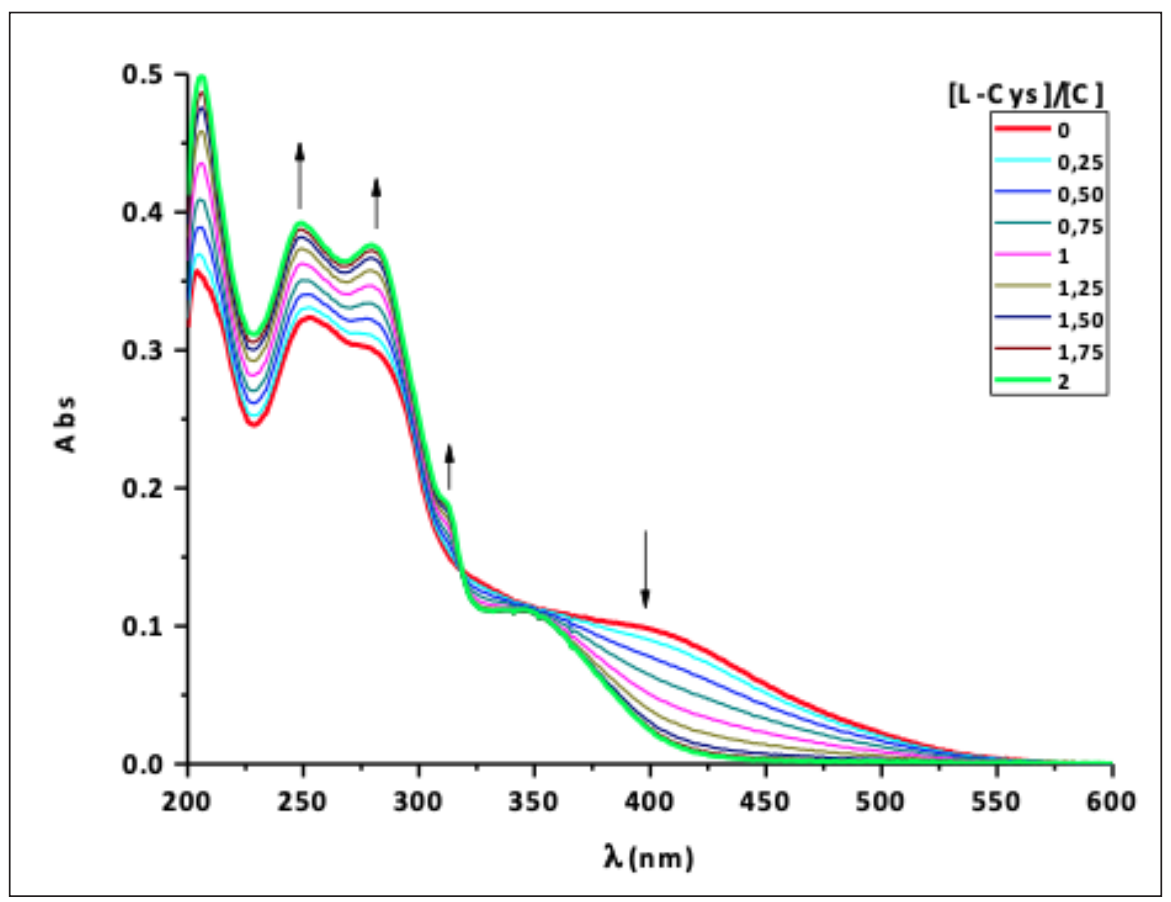

Figure 11. UV-Vis spectral changes with the addition of $L$-Cys at different ratios $[L-C y s] /[C]$ where $\mathrm{C}$ is the molar concentration of $(8)$ in $\mathrm{H}_{2} \mathrm{O} / \mathrm{CH}_{3} \mathrm{CN}(1: 1)$.

When adding excess sodium dithionite (a strong reductant of formula $\mathrm{Na}_{2} \mathrm{~S}_{2} \mathrm{O}_{4}$ ) to a solution of $(8)$ in a $\mathrm{CH}_{3} \mathrm{CN} /$ $\mathrm{H}_{2} \mathrm{O}$ mixture (300:1), the UV-Vis spectrum, as shown in Figure 12, displays the same changes as those described before upon reduction with $L$-Cys. However, after reduction with dithionite, the emission intensity is enhanced by an order of magnitude in comparison with the non-reduced complex, as shown in Figure 13. An explanation for this emission enhancement effect, which is absent in the $L$-Cys reduced product, is based on the fact that the concentration of water is much higher in the former case. Water may quench the emission from the ${ }^{3}$ MLCT excited state by protonation of the reduced azo moiety.

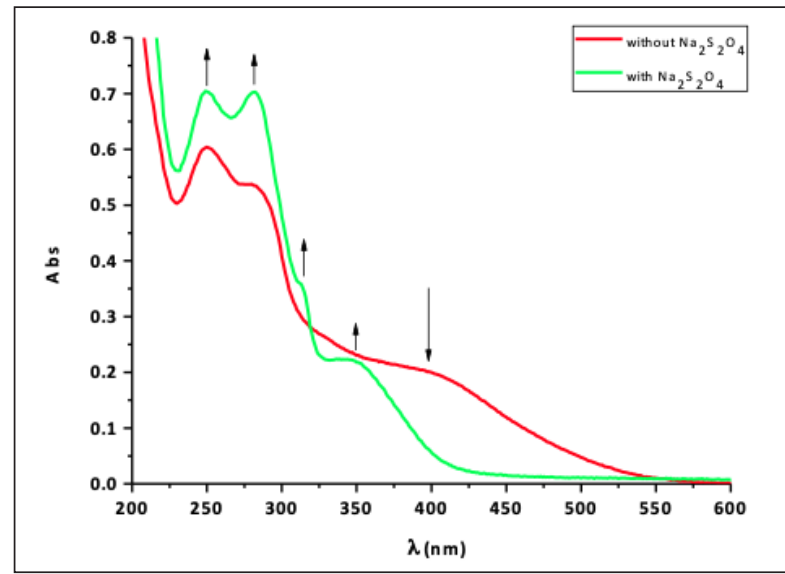

Figure 12. Changes in the UV-Vis spectrum of (8) upon addition of $\mathrm{Na}_{2} \mathrm{~S}_{2} \mathrm{O}_{4}$, to $\mathrm{CH}_{3} \mathrm{CN} / \mathrm{H}_{2} \mathrm{O}(300: 1)$. 


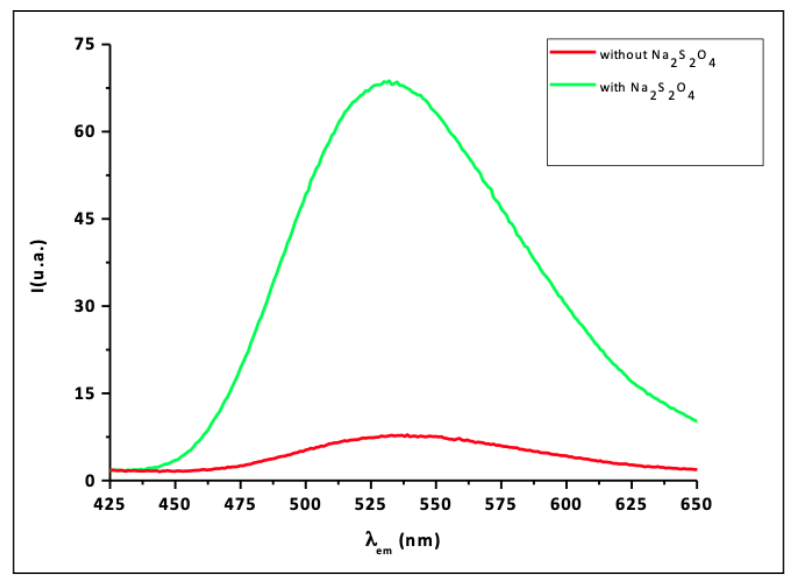

Figure 13. Changes in the emission spectrum of (8) upon addition of $\mathrm{Na}_{2} \mathrm{~S}_{2} \mathrm{O}_{4}$ to $\mathrm{CH}_{3} \mathrm{CN} / \mathrm{H}_{2} \mathrm{O}(300: 1)$.

It can be concluded that complex (8) acts an "on-off" molecular switch, a property reflected in the observed large changes in both absorption and emission spectra when adding a strong reductant such as dithionite in $\mathrm{CH}_{3} \mathrm{CN} / \mathrm{H}_{2} \mathrm{O}(300: 1)$ solutions.

As shown in Figure 14, dual emission has been detected for complex (8) in pure $\mathrm{CH}_{3} \mathrm{CN}$. At $\lambda_{\text {exc }}=346 \mathrm{~nm}$, a weak emission is observed at $\lambda_{\text {em }}=530 \mathrm{~nm}$ ( with quantum yield $\varphi=3 \times 10^{-4}$ ), which can be attributed to a decay from a ${ }^{3} \mathrm{MLCT}$ $\mathrm{d}_{\pi}(\mathrm{Re})-\pi^{*}$ excited state with the $\pi^{*}$ orbitals centered at the bipyridyl rings. At $\lambda_{\text {exc }}=400 \mathrm{~nm}$, a new emission appears at $\lambda_{\text {em }}$ $=575 \mathrm{~nm}$ (with a similar quantum yield), which can be ascribed to a decay from a ${ }^{3} \mathrm{MLCT} \mathrm{d}_{\pi}(\mathrm{Re})-\pi^{*}$ excited state with the $\pi^{*}$ orbitals centered at the azo bridging group. At room temperature, emission bands of tricarbonylpolypyridylrhenium(I) complexes are normally non-structured, so that this dual emission cannot be ascribed to coupling to vibrational modes. Although azopyridines usually undergo cis-trans isomerization when applying UV and/or visible light, we irradiated samples of complex (8) in a $\mathrm{CH}_{3} \mathrm{CN}$ solution at $\lambda_{\text {exc }}=270 \mathrm{~nm}$ for a couple of hours and no changes in absorption or emission spectra were detected, in agreement with previous reports on $\mathrm{Ru}$ complexes with 4,4'-azopy. ${ }^{13}$ This result evidenced that isomerization cannot account for the two nearly isoenergonic emissions.

It must be noted that we found emission in complexes containing $4,4^{\prime \prime}$-azobpy as the only chromophoric ligand for the first time. In Ru or Os bipyridyl species of 4,4" -azobpy, this luminescence is masked by the strong emission originated from ${ }^{3} \mathrm{MLCT}_{\pi}(\mathrm{M})-\pi^{*}$ excited states $\left(\mathrm{M}=\mathrm{Ru}\right.$ or Os) with the $\pi^{*}$ orbitals centered at the auxiliary $2,2^{\prime}$-bipyridyl ligands. ${ }^{17}$

Figure 15 shows the fit of both decays as measured by TCSPC with two lifetimes: $\tau=(16 \pm 1) \mathrm{ns}$ for the decay at $\lambda_{\mathrm{em}}=530 \mathrm{~nm}$ and $\tau=(621 \pm 7) \mathrm{ns}$ for the decay at $\lambda_{\mathrm{em}}=575 \mathrm{~nm}$. The excitation wavelength $\left(\lambda_{\mathrm{exc}}=390 \mathrm{~nm}\right)$ was close to the value of the absorption maximum of the lowest energy MLCT. The results were similar when using an excitation wavelength $\left(\lambda_{\text {exc }}=340 \mathrm{~nm}\right)$ close to the value of the higher energy MLCT, but the weighting factor of the lower lifetime is much higher, supporting its assignment to the emission at $\lambda_{\mathrm{em}}=530 \mathrm{~nm}$.

Both the quantum yield and the lifetime for the first decay are much lower than those reported for similar Re(I) species, indicating luminescence quenching by crossing to a second MLCT state, which in turn decays with a low quantum yield due to quenching of the bridging ligand by excited states. The longer lifetime may be due to increased delocalization on the bridging ligand 4,4"-azobpy as compared to bpy. It is well known that excited states lifetimes in this type of complexes can be increased when IL transitions are involved. TD-DFT calculations, described in the following paragraph, support the conclusion that the lowest-energy emission originates from an excited state with the LUMO centered on the azo moiety. 


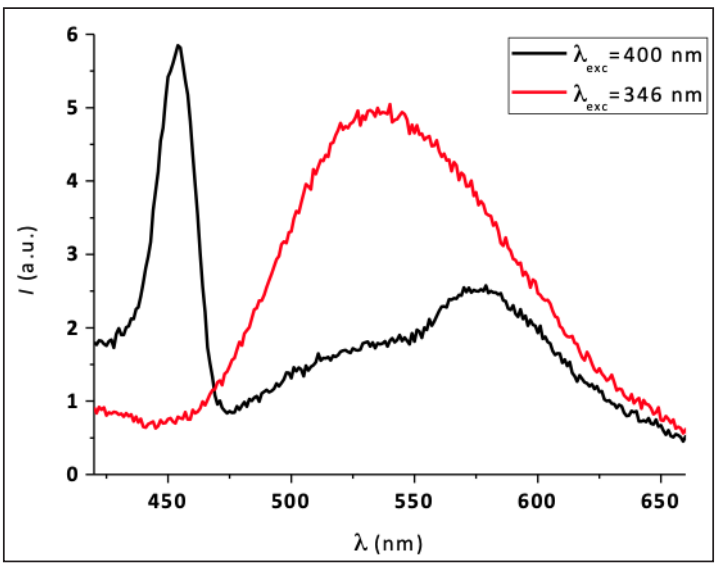

Figure 14. Emission spectra of $(\mathbf{8})$ in deareated $\mathrm{CH}_{3} \mathrm{CN}$, at room temperature and at two excitation wavelengths (the red line corresponds to $\lambda_{\mathrm{exc}}=346 \mathrm{~nm}$ and the black line, to $\lambda_{\mathrm{exc}}=400 \mathrm{~nm}$ ). The band at $\lambda_{\mathrm{em}}=450 \mathrm{~nm}$ is a Raman band of $\mathrm{CH}_{3} \mathrm{CN}$.

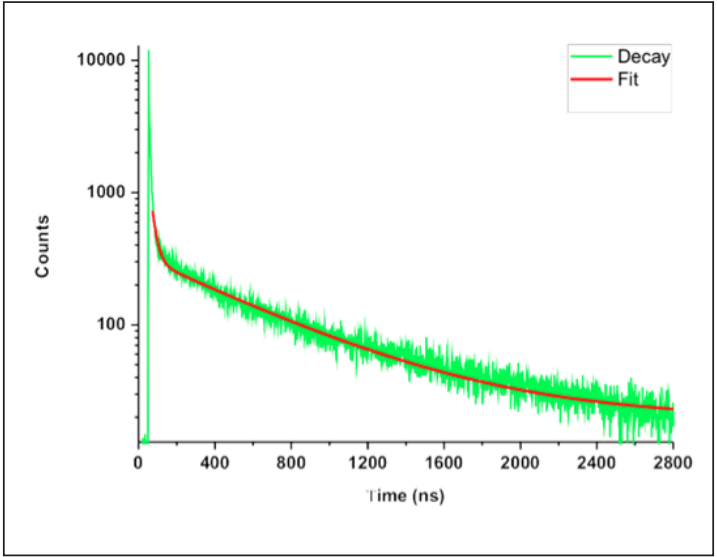

Figure 15. TCSPC decays of excited states of $(\mathbf{8})$ in deareated $\mathrm{CH}_{3} \mathrm{CN}$, at room temperature and $\lambda_{\mathrm{exc}}=390 \mathrm{~nm}$.

TD-DFT calculations were done for both complex $(\mathbf{8})$ and its reduced and protonated form (hydrazine bridge). Scheme 5 shows the energy level diagrams together with figures for some frontier MO's. The LUMO for complex (8) is centered on the azo moiety of $4,4^{\prime \prime}$-azobpy, while that of the reduced and protonated species $\left(\mathbf{8 H}_{\mathbf{2}}\right)$ is centered on the bipyridyl rings of 4,4" -azobpy. These findings are consistent with the spectroscopic and photophysical properties described before. However, when a strong reductant such as dithionite is added in acetonitrile/water (v/v, 300/1), the emission is enhanced by one order of magnitude (see Fig. 13), since the LUMO becomes centered on the bipyridyl rings. Additionally, the MO energy diagrams in Scheme 5 indicate that the difference between the LUMO and the HOMO in the reduced/protonated form are almost equal to the difference between the LUMO+1 and the HOMO in complex (8), so that both emissions (originated from a MLCT excited state centered on the bipyridyl rings) are expected to occur at almost the same energies.

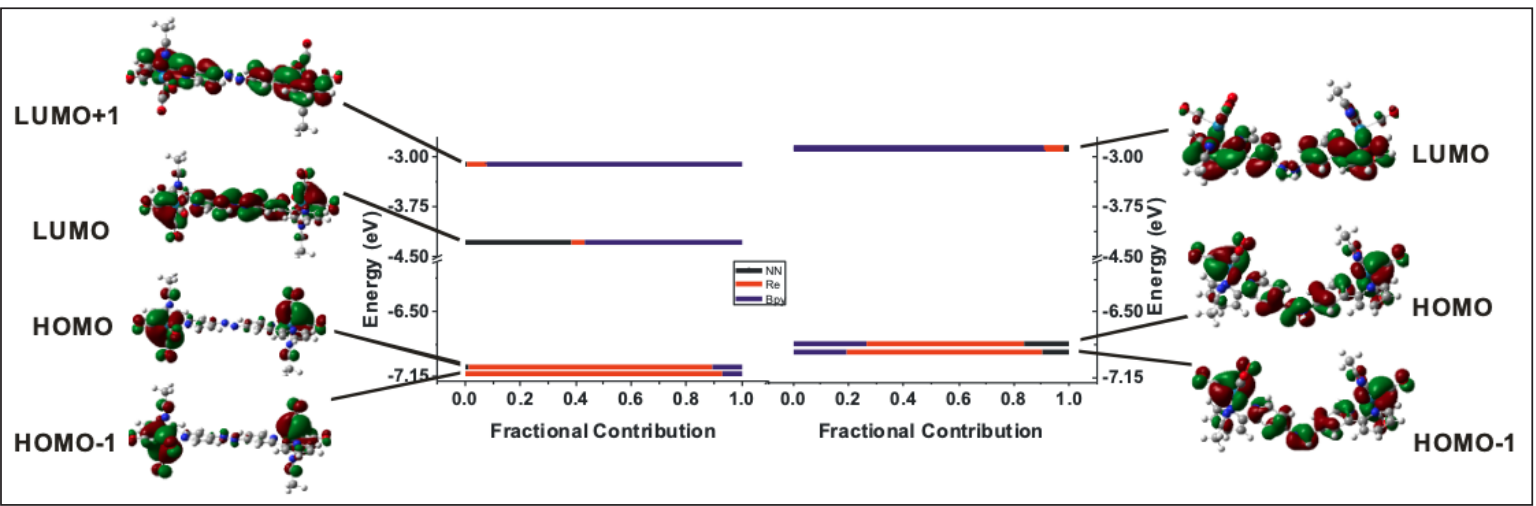

Scheme 5. MO energy diagrams for complex $(\mathbf{8})$ (left) and for the doubly reduced and protonated species $\left(\mathbf{8} \mathbf{H}_{2}\right)$ (right). 
Another example of the importance of using both spectroelectrochemical and photophysical data to infer the nature of charge-transfer excited states in molecules that can act as sensors or "molecular switches" is a new mononuclear $\mathrm{Ru}$ complex with formula $\mathrm{K}_{2}\left[\mathrm{Ru}(\mathrm{L})(\mathrm{CN})_{4}\right]$, (9), with $\mathrm{L}=4,4$ "'-azobis-(2,2'-bipyridine), that we recently prepared and characterized by spectroscopic, electrochemical and photophysical techniques. ${ }^{18}$ The structure of the anion in (9) is shown in Scheme 6. The use of $\left[\mathrm{Ru}(\mathrm{L})(\mathrm{CN})_{4}\right]^{2-}$ species as sensors of biological relevant analytes has not been widely explored, and the azo function is one of the most versatile functional units due to its sensitivity to the addition of electrons, protons or photons. ${ }^{12,13,17,19}$ The use of (9) as a water soluble probe for $L$-Cys detection by means of its remarkable spectroscopic changes upon reduction and subsequent protonation has also been successfully explored. ${ }^{18}$

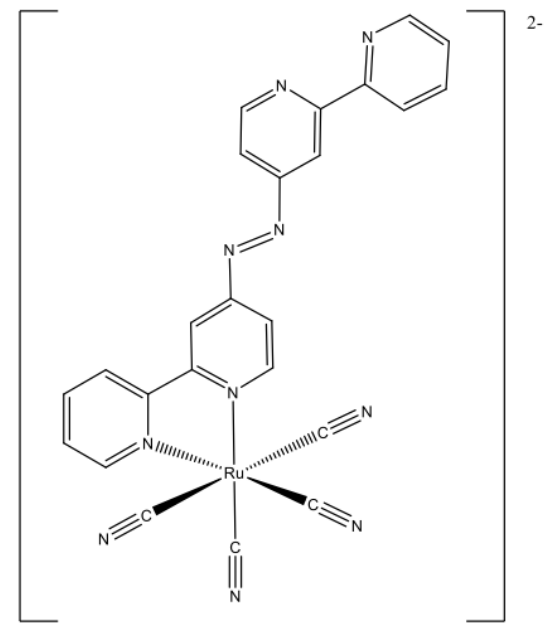

Scheme 6. Anion structure in complex (9).

In effect, as shown in Figure 16, when excess $L$-Cys is added to an aqueous solution of (9), the intensity of the lowest energy absorption band of its UV-Vis spectrum (at $\lambda_{\max }=497 \mathrm{~nm}$ ) decreases. There is also an increase in IL band absorbance at $\lambda_{\max }=242 \mathrm{~nm}$, and a new band appears at $\lambda_{\max }=394 \mathrm{~nm}$ after $10 \mathrm{~min}$. Three isosbestic points are detected at $\lambda=313,370$ and $418 \mathrm{~nm}$. Moreover, the changes induced by reduction with $L$-Cys are fully reversible; the original spectrum of (9) can be fully recovered by the addition of one drop of a 1:5 $\mathrm{H}_{2} \mathrm{O}_{2}$ /water solution. The mechanism of azo compounds reduction in an aqueous solution is well known, and the formed product is the hydrazo species - HN-NHwhen using dithionite as reducing agent; ${ }^{20}$ recently, Zeng et al. ${ }^{21}$ reported the same results for Ru complexes having $\mathrm{L}$ as bridging ligand and using GSH as reductant.

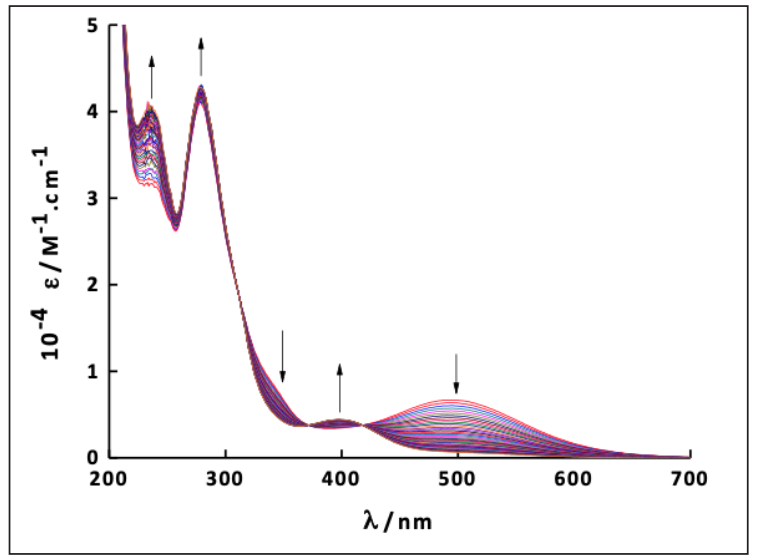

Figure 16. UV-Vis spectral changes upon addition of an $L$-Cys excess to an aqueous solution of $(9)\left(C=5.1 \times 10^{-5} \mathrm{M}\right)$. The arrows indicate the evolution of spectra from $t=0$ to $t=10 \mathrm{~min}$.

When an external potential of value $V=-800 \mathrm{mV}$ is applied to a spectroelectrochemical cell containing an aqueous solution of $(9)\left(\mathrm{C}=3.8 \times 10^{-5} \mathrm{M}\right)$, the intensities of the bands in the UV region increase, with greater changes being 
observed for the band at $\lambda_{\max }=242 \mathrm{~nm}$. In the visible region, the intensity of the band at $\lambda_{\max }=497 \mathrm{~nm}$ decreases, while a new band emerges at $\lambda_{\max }=394 \mathrm{~nm}$. Identical isosbestic points, as shown in Figure 16, are detected. The original spectrum was restored when a potential of $0 \mathrm{~V}$ was applied for $10 \mathrm{~min}$ after reduction.

This is the first report of applying the spectral changes originated from a double PCET (proton-coupled electron transfer) process of an azo group in a bipyridyl ligand coordinated to a tetracyanoruthenium(II) moiety, as shown in Scheme 7, for molecular sensing purposes, in particular for detecting the biologically relevant analyte $L$-Cys. We have only performed these experiments at neutral $\mathrm{pH}$ but, considering that detecting thiols in living cells is a highly relevant issue in biochemistry, ${ }^{22,23}$ we propose to extend these studies including $\mathrm{pH}$ effects on the sensitivity of detection of $L$-Cys and similar biological reductants such as GSH. Since the analytical method described here is of the kinetic mode, we hope that selectivity will be eventually achieved by fixing different times of detection. Additionally, it can be envisaged that these types of complexes may be useful for detecting the related "smallest thiol", $\mathrm{H}_{2} \mathrm{~S} / \mathrm{HS}^{-}$, which has an important physiological role as a signaling agent. ${ }^{24}$ More possibilities arise when considering the fact that thiolates can be used as ligands in redox-active transition metal complexes with a biochemical behavior connected with other crucial physiological messengers such as NO. ${ }^{25}$ The diverse uni- or multi-electron transfers in which both compounds are involved in aqueous solutions generate intermediate species whose structure and reactivity have to be studied in order to understand biological responses. On the other hand, the photochemical behavior of these species could be an interesting area to be further explored.

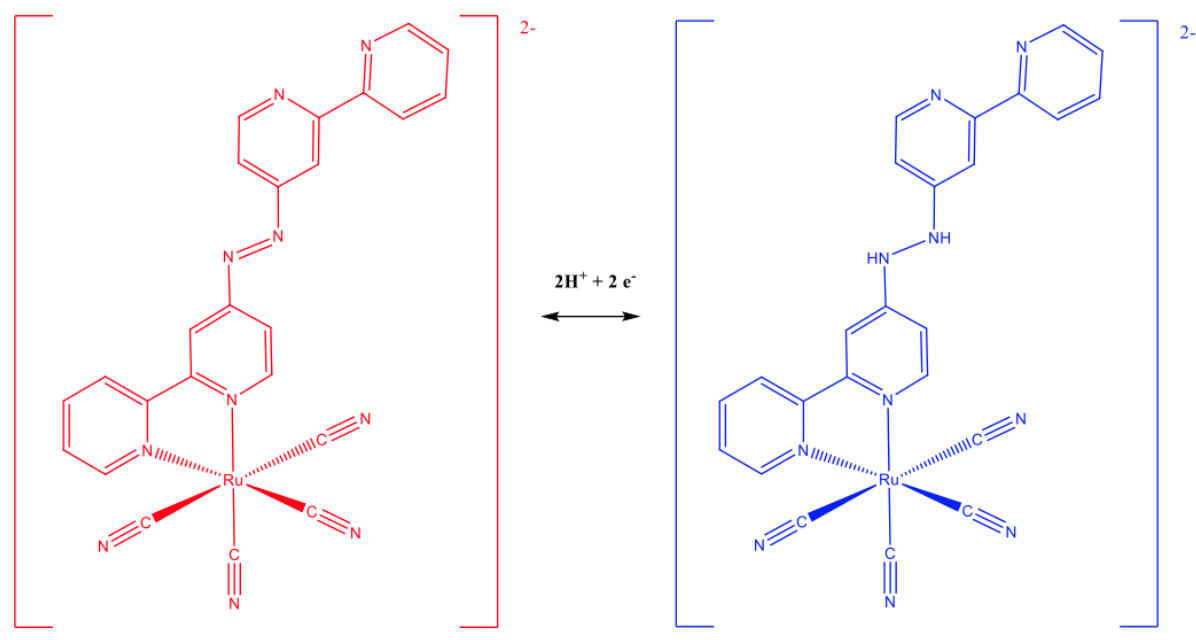

Scheme 7. PCET process between complex (9) (red) and complex (9H2) (blue).

Complex (9) does not emit in water at r.t., since the azo group of 4,4" -azobpy can quench the radiative decay from the lowest ${ }^{3}$ MLCT excited state. Reviving the emission can be achieved by introducing an electron in the $\pi^{*}$ orbital mainly localized on the bridging group $(-\mathrm{N}=\mathrm{N}-)$ so that the non-radiative decay path is suppressed. Upon reduction and protonation of (9), the emission is turned on. This "off-on" switching behavior - based on a different mechanism - has been described before for $\mathrm{Ru}$ (II) and Ir (I) complexes in the sensing of thiols. ${ }^{22,23}$

As shown in Figure 17, there is no emission in (9), but upon reduction and protonation of the azo group to form the species (9H2), emission appears at $\lambda_{\mathrm{em}}=610 \mathrm{~nm}\left(\lambda_{\mathrm{exc}}=394 \mathrm{~nm}\right)$. The quantum yield of (9H2) in water is $\phi=0.0027$, which is about half the value observed for the related complex $\left[\mathrm{Ru}(\mathrm{bpy})(\mathrm{CN})_{4}\right]^{2-} .^{26}$

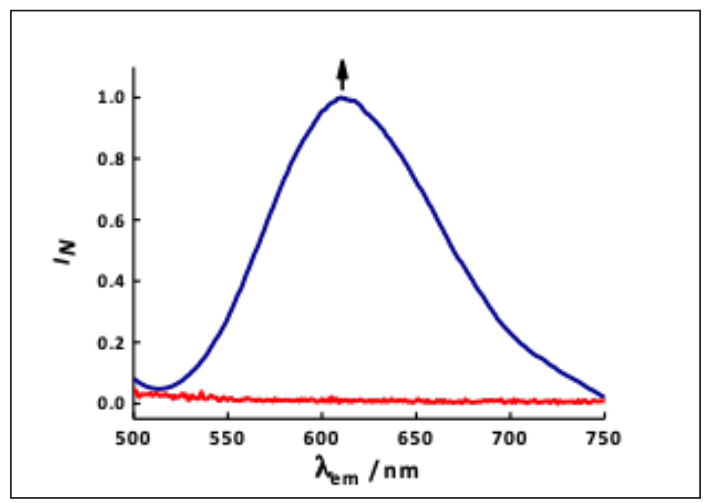

Figure 17. Normalized emission spectra of (9) (red) and (9H2) (blue) in water ( $\lambda_{\text {exc }}=394 \mathrm{~nm}$ ) at r.t. 
Excellent linear correlations were found between the absorbance changes of $(9)\left(C \approx 10^{-5} \mathrm{M}\right)$ at $\lambda=497 \mathrm{~nm}$ and $[L$-Cys] after $5 \mathrm{~min}$, as well as between emission changes at $\lambda=610 \mathrm{~nm}$ and $[L$-Cys $]$ after $5 \mathrm{~min}$. From these plots, detection of $L$-Cys at the submillimolar level can be made. It should be noted that emission and absorption properties of cyano-ruthenium complexes are extremely solvent-dependent due to strong interactions of the cyanide co-ligands with solvents of different acceptor numbers; therefore, the nature of the involved electronic states can also be modulated by solvent changes. ${ }^{27}$

For a reasonable explanation of the absorption and emission properties of (9) and its reduced and protonated form (9H2), quantum mechanical calculations were carried out. The MO's diagrams of (9), and (9H2) - built with DFT calculations - are shown in Figures 18 and 19, together with the contributions of each group.

Figure 18 shows that the HOMO in (9) is localized in the metal with contributions of the coordinated cyano groups, while the LUMO is located mainly in the azo bridge of $\mathrm{L}=4,4^{\prime \prime}$-azobpy; on the other hand, the LUMO+1 MO has more contributions of the bpy ring. Thus, the lowest energy visible absorption band is expected to be a MLCT Ru $\rightarrow \mathrm{L}$, with $\mathrm{L}$ having an important contribution from the azo bridge, while the second band at higher energy can be assigned to a similar MLCT Ru $\rightarrow$ L, with L having an important contribution from the bpy ring.

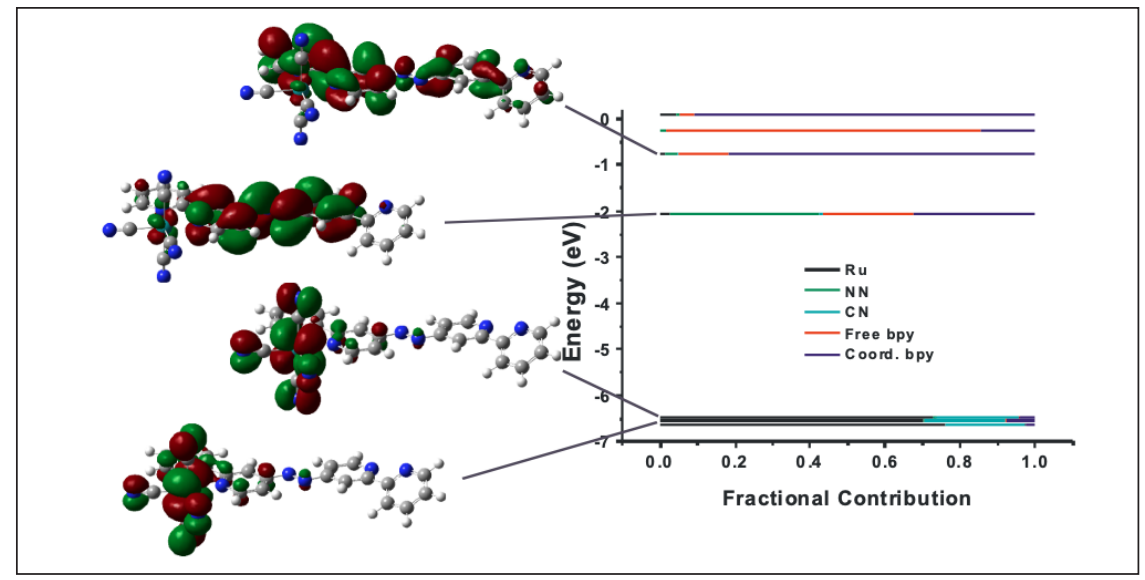

Figure 18. MO energies and electron density diagrams for the two highest HOMOs and two lowest LUMOs in (9). Different group contributions are marked by different colors.

Figure 19 shows the MO diagrams in (9H2). The effect of the first one-electron reduction, as proposed before, is filling the $\pi^{*}$ orbital centered on the azo bridge. Upon reduction and protonation to form the hydrazo form, the complex adopts a torsioned configuration, which implies rotation trough the -HN-NH- bond as depicted in the same Figure.

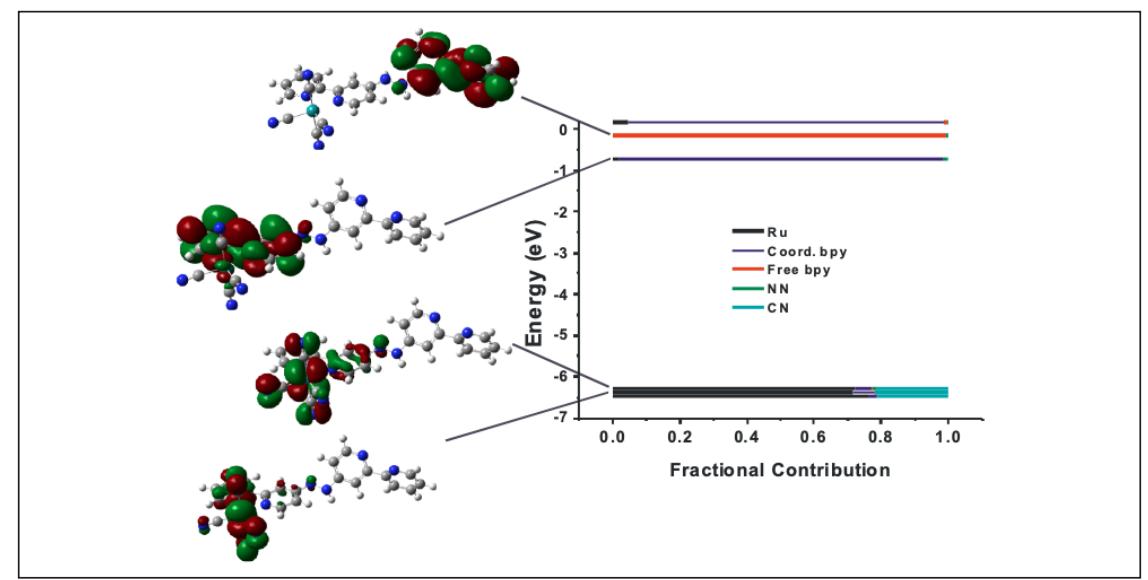

Figure 19. MOs energies and electron density diagrams for the two highest HOMOs and two lowest LUMOs in (9H2). Different group contributions are marked by different colors. 
All these assignments were corroborated by calculations at the TD-DFT level. The calculated UV-Vis spectrum of (9) presents reasonable agreement with its experimental spectrum, as shown in Figure 20.

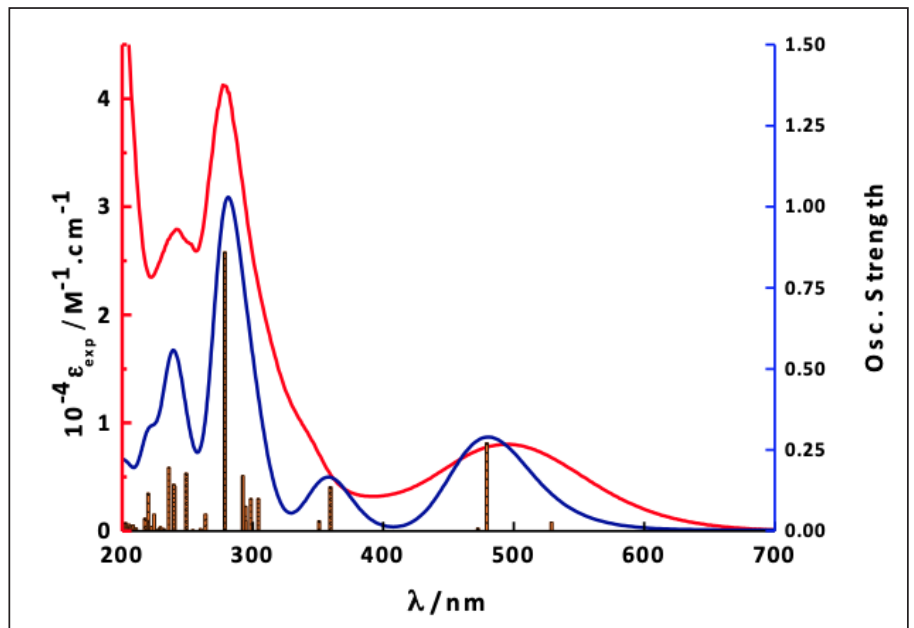

Figure 20. Experimental (red plot) and calculated (blue plot) UV-Vis spectrum of (9) in water at r.t.

TCSPC measurements were carried out to explore the nature of the excited states of (9H2). The lifetime of the ${ }^{3} \mathrm{MLCT}$ excited state of the reduced and protonated form of (9), obtained by reduction with $L$-Cys in aqueous media (Tris buffer, $\mathrm{pH}=7.5$ ), was determined by following the emission decay at $\lambda=610 \mathrm{~nm}$ after pulse excitation at $\lambda=390 \mathrm{~nm}$. The decay of the ${ }^{3}$ MLCT emission showed a double exponential behavior. The shortest lifetime $\left(\tau_{1}=9.7 \mathrm{~ns}\right)$ was assigned to the decay from the ${ }^{3}$ MLCT excited state of the cis form of (9H2), while the longer one $\left(\tau_{2}=75 \mathrm{~ns}\right)$ was assigned to a decay from a similar state of the trans isomer. These assignments were supported by DFT and TD-DFT calculations of (9H2) for the cis and trans isomers, that revealed the presence of two lowest triplets for each isomer, with that of the trans form being at a higher energy that that of the $c i s$ form. This is the expected result, according to the energy gap law. ${ }^{28}$

We conclude that the "on-off" behavior of complex (9) can be successfully applied for the determination of the biologically relevant analyte $L$-Cys at the submillimolar range in water. The spectral changes originated from the Ru4,4 "'-azobpy excited state originated upon reduction and protonation of the azo group can be explained by quantum mechanical calculations.

\section{Conclusions}

We conclude that both spectroelectrochemical and photophysical experiments are complementary in elucidating the nature of light-induced charge-transfer excited states in transition metal complexes that are pertinent in energy conversion or chemical sensing. Simultaneously resorting to these experimental techniques and using quantum mechanical calculations to interpret the obtained results can lead to successful designs of new sensitizers for solar cells or of new chemical sensors for analytes relevant in medical diagnosis and treatment.

To extend the concept introduced by Kaim of using the best of two worlds (reaction-oriented electrochemistry with species-focused spectroscopy) $)^{1}$ to analyze redox reactions in general, we tried to show here the best of three worlds (spectroscopy, electrochemistry and photophysics) to characterize the nature of light-induced excited states, an issue which can be considered as a metaphor of a scientific contribution from a far "third world" country.

\section{Acknowledgements}

I wish to thank all my collaborators at INQUINOA, INBIONATEC and INFINOA for their important scientific contributions. Financial support from ANPCyT, CONICET and UNT are gratefully acknowledged. N. E. K. is a Member of the Research Career (CONICET). 


\section{References}

[1] W. Kaim, and J. Fiedler. Spectroelectrochemistry: the best of two worlds. Chem. Soc. Rev. 38: 3373-3382, 2009.

[2] P. M. Keane, J. Tory, M. Towrie, I. V. Sazanovich, C. J. Cardin, S. J. Quinn, F. Hartl, J. M. Kelly, and C. Long. Spectro-electrochemical Studies on $\left[\operatorname{Ru}(T A P)_{2}(d p p z)\right]^{2+}$ - Insights into the Mechanism of its Photosensitized Oxidation of Oligonucleotides. Inorg. Chem. 58: 663-671, 2019.

[3] J. H. Mecchia Ortiz, N. Vega, D. Comedi, M. Tirado, I. Romero, X. Fontrodona, T.Parella, F. E. Morán Vieyra, C. D. Borsarelli, and N. E. Katz. Improving the Photosensitizing Properties of Ruthenium Polypyridyl Complexes. Inorg. Chem. 52: 4950-4962, 2013.

[4] C. E. McCusker, and J. K. McCusker. Synthesis and spectroscopic characterization of CN-substituted bipyridyl complexes of Ru (II). Inorg. Chem. 50: 1656-1669, 2011.

[5] W. R. Browne, C. G. Coates, C. Brady, P. Matousek, M. Towrie, S. W. Botchway, A. W. Parker, J. G. Vos, and J. J. McGarvey. The Early Picosecond Photophysics of Ru(II) Polypyridyl Complexes: A Tale of Two Timescales. J. Am. Chem. Soc. 125: 1706-1707, 2003.

[6] L. O’Neill, L. Perdisatt, and C. O’Connor. Influence of Auxiliary Ligands on the Photophysical Characteristics of a Series of Ruthenium(II)-Polypyridyl Complexes. J. Phys. Chem. A 116: 10718-10735, 2012.

[7] N. M. O’Boyle, A. L. Tenderholt, and K. M. Langner. Cclib: a library for package-independent computational chemistry algorithms. J. Comp. Chem. 29: 839-845, 2008. Available from: http://gausssum.sf.net.

[8] J. H. Mecchia Ortiz, C. Longo, and N. E. Katz. Polypyridyl ruthenium complexes containing anchoring nitrile groups as $\mathrm{TiO}_{2}$ sensitizers for application in solar cells. Inorg. Chem. Comm. 55: 69-72, 2015.

[9] F. F. Salomón, N. C. Vega, T. Parella, F. E. Morán Vieyra, C. D. Borsarelli, C. Longo, M. Cattaneo, and N. E. Katz, manuscript in revision.

${ }^{[10]}$ J. H. Mecchia Ortiz, F. E. Morán Vieyra, C. D. Borsarelli, I. Romero, X. Fontrodona, T. Parella, N. D. Lis de Katz, F. Fagalde, and N. E. Katz. Mono- and Dinuclear Complexes of Tricarbonylrhenium(I) with 4-Methyl-2,2'-bipyridine4'-carbonitrile. Eur. J. Inorg. Chem. 2014(21): 3359-3369, 2014.

${ }^{[11]}$ K. Kalyanasundaram. Luminescence and Redox Reactions of the Metal-to-ligand Charge-transfer Excited State of Tricarbonylchloro(polypyridyl)rhenium(I) Complexes. J. Chem. Soc. Faraday Trans. 2. 82: 2401-2415, 1986.

${ }^{[12]}$ P. O. Abate, G. Pourrieux, F. E. Morán Vieyra, M. Cattaneo, M. Vergara, and N. E. Katz. A new molecular switch based on a symmetrical dinuclear complex of two tricarbonylrhenium(I) moieties bridged by 4,4"-azobis-(2,2'-bipyridine). Polyhedron, 21: 3359-3369, 2018.

${ }^{[13]}$ G. Pourrieux , F. Fagalde, I. Romero, X. Fontrodona, T. Parella, and N. E. Katz. Electron-, Proton-, and PhotonInduced Spectroscopic Changes in Chromophore-Quencher Tricarbonyl(2,2'-Bipyridine)rhenium(I) Complexes with 4,4'-Azobis (pyridine). Inorg. Chem. 49: 4084-4091, 2010.

${ }^{[14]}$ P. Atkins, and J. de Paula. Physical Chemistry, Oxford University Press, Oxford, United Kingdom, $8^{\text {th }}$. Ed., 2006.

${ }^{[15]}$ D. M. Dattelbaum, K. M. Omberg, J. R. Schoonover, R. L. Martin, and T. J. Meyer. Application of Time-Resolved Infrared Spectroscopy to Electronic Structure in Metal-to-Ligand Charge-Transfer Excited States. Inorg. Chem. 41(23): 6071-6079, 2002.

${ }^{[16]}$ D. Maheshwaran, S. Priyanga, and R. Mayilmurugan. Copper(II)-benzimidazole complexes as efficient fluorescent probes for L-cysteine in water. Dalton Trans. 46 : 11408-11417, 2017.

[17] J. Otsuki, K. Sato, M. Tsujino, N. Okuda, K. Araki, and M. Seno, M. Ruthenium Complexes Containing an Azobipyridine Ligand as Redox-Responsive Molecular Switches. Chem. Lett. 25: 847-848, 1996. 
${ }^{[18]}$ P. O. Abate, G. Pourrieux, F.E. Morán Vieyra,C. D. Borsarelli, T. Parella, M. M. Vergara, and N. E. Katz, A Novel Mononuclear Complex of 4,4"'-azobis(2,2'-bipyridine) Coordinated to Tetracyanoruthenium(II) Can Behave as a "Molecular Switch". Polyhedron 174: 114149, 2019.

${ }^{[19]}$ V. Gonzalez, T. Wilson, I. Kurihara, A. Imai, J. A. Thomas, and J. Otsuki. A dinuclear ruthenium(II) complex that functions as a label-free colorimetric sensor for DNA. Chem. Commun. 1868-1870, 2008.

${ }^{[20]}$ A. H. Gemeay. Kinetics and mechanism of the reduction of some azo-dyes by inorganic oxysulfur compounds. Dyes and Pigments, 54: 201-212, 2002.

${ }^{[21]}$ L. Zeng, S. Kuang, G. Li, C. Jin, L. Ji, H. Chao. A GSH-activatable ruthenium(II)-azo photosensitizer for two-photon photodynamic therapy. Chem. Commun. 53: 1977-1980, 2017.

${ }^{[22]}$ G.-Y. Li, J-P. Liu, H. Y. Huang, Y. Wen, H. Chao, and L-N. Ji. Colorimetric and luminescent dual-signaling responsive probing of thiols by a ruthenium(II)-azo comple. J. Inorg. Biochem. 121:108-113, 2013.

${ }^{[23]}$ G. Li, Y. Chen, J. Wu, L. Ji, and H. Chao. Thiol-specific phosphorescent imaging in living cells with an azobis(2,2bipyridine)-bridged dinuclear iridium(III) complex. Chem. Commun. 49: 20140-2042, 2013.

${ }^{[24]}$ H. Kimura, N. Shibuya, and Yuka Kimura. Hydrogen Sulfide Is a Signaling Molecule and a Cytoprotectant. Antioxidants \& Redox Signaling, 17: 45-57, 2012.

[25] J. P. Marcolongo, A. Zeida, L. D. Slep, and J. A. Olabe. Thionitrous Acid/Thionitrite and Perthionitrite Intermediates in the "Crosstalk" of NO and $\mathrm{H}_{2} \mathrm{~S}$. Advances in Inorganic Chemistry, 70: 277-309, 2017.

${ }^{[26]}$ C. A. Bignozzi, C. Chiorboli, M. T. Indelli, M. A. Rampi Scandola, G. Varani and F. Scandola. Simple poly(pyridine) ruthenium(II) photosensitizer: (2,2'-bipyridine) tetracyanoruthenate(II). J. Am. Chem. Soc. 108: 7872-7873, 1986.

[27] M. E. García Posse, N. E. Katz, L. M. Baraldo, D. Polonuer, C. Colombano, and J. A. Olabe. Comparative Bonding and Photophysical Properties of 2,2'-bipyridine and 2,2'-bipyrazine in Tetracyano Complexes Containing Ruthenium and Osmium. Inorg. Chem. 34: 1830- 1835, 1995.

${ }^{[28]}$ J. V. Caspar, E. M. Kober, B. P. Sullivan, and T. J. Meyer. Application of the energy gap law to the decay of chargetransfer excited states. J. Am. Chem. Soc. 104: 630-632, 1982.

\section{Bio}

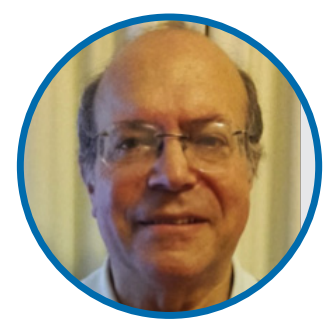

\section{Néstor E. Katz}

Néstor E. Katz graduated as Doctor in Chemistry in 1978, with a thesis directed by Dr. Pedro J. Aymonino at UNLP. He completed his postdoctoral studies with Dr. Norman Sutin and Dr. Carol Creutz at BNL, USA, and with Dr.
Thomas J. Meyer at UNC at Chapel Hill, USA. He has directed 8 doctoral theses and published 86 papers on the synthesis and properties of new coordination compounds of iron, cobalt, ruthenium, osmium and rhenium that are relevant to energy conversion and chemical sensing. He is Full Professor of Physical Chemistry at UNT, Principal Researcher at CONICET and Director of INQUINOA (CONICET-UNT). 